\title{
Degradation of PEO in the Solid State: A Theoretical Kinetic Model
}

\author{
Pascal de Sainte Claire* \\ Laboratoire de Photochimie Moléculaire et Macromoléculaire, UMR CNRS 6505, Clermont Universités \\ (ENSCCF), Université Blaise Pascal, F-63177, Aubière, France
}

Received November 4, 2008; Revised Manuscript Received March 6, 2009

\begin{abstract}
The quantitative kinetic model presented in this work provides insights of the inner mechanisms that play a key role in the natural oxidative degradation (photoinduced and thermal) of a model polymer, polyethylene oxide (PEO). A set of key reactions is selected from ab initio data, theoretical rate constant calculations, and experimental rate constants. Experimental results, i.e., induction times and quantities of carbonyl end-products, are accurately reproduced by this model. While this study grasps the complexity of the degradation mechanism, results depend mainly on the reactivity of peroxy radicals and that of hydroperoxide groups. Three pathways are available to the peroxy species, i.e., intermolecular and $\gamma$-intramolecular $\mathrm{H}$-abstraction reactions, and the termination reaction. The competition between these processes is the driving force of the degradation mechanism. Moreover, in thermo-oxidative conditions, the relative quantities of esters and formates depend strongly on four competitive hydroperoxide decomposition channels, i.e., the unimolecular, bimolecular, induced decomposition by hydroxyl radicals and the hydroperoxide $\mathrm{H}$-abstraction reaction. Many of the reactions investigated here participate also in polymer synthesis, pyrolysis or other degradation processes. Moreover, the simple structure of the model polymer in this work is representative of a wide range of polymer systems.
\end{abstract}

\section{Introduction}

Polyethylene oxide (PEO) plays a significant role in many industrial applications (paints, coatings, polymer electrolytes, thermal energy storage materials,...). As a nontoxic biodegradable soluble polymer, its industrial use in the pharmaceutical field, the packaging industry, or as a lubricant is of considerable importance as well. ${ }^{1-3}$ Although the degradation of PEO in pyrolysis conditions is well documented ${ }^{4-9}$ the natural aging mechanism in thermo- ${ }^{10-14}$ and photo-oxidative ${ }^{14-17}$ conditions is not clearly understood.

It is well established that PEO degradation proceeds by the random chain scission of $\mathrm{C}-\mathrm{O}$ bonds. ${ }^{4,5,10,18,19}$ At high temperatures (pyrolysis conditions), significant $\mathrm{C}-\mathrm{C}$ bond cleavage is also observed. ${ }^{5,7}$ The activation energy of the overall degradation process was measured between 30 and $50 \mathrm{kcal} /$ mol for high molecular weight samples. ${ }^{4,20,21}$ Such values are smaller than $\mathrm{C}-\mathrm{O}$ bond strengths $(\sim 80 \mathrm{kcal} / \mathrm{mol}$ in $\mathrm{PEO})$ because in the actual process, there is competition between $\mathrm{C}-\mathrm{O}$ bond breakage, radical/radical recombination reactions (polymer cross-linking for example) and abstraction reactions that involve light radical species. For example, specific $\mathrm{H}$-abstraction reactions of hydroxyl radicals proceed with negative activation energy. ${ }^{22}$ In addition, the pyrolysis of low molecular weight polymers is kinetically controlled by desorption/evaporation of small volatile products. ${ }^{7}$ In that case, the overall activation energy is much smaller, i.e. $10-20 \mathrm{kcal} / \mathrm{mol}$. The degradation products from pyrolysis experiments were identified as monoand diether oligomers, vinyl ethers, carboxylic acids and oxymethylene species. ${ }^{6,8,23}$ Aldehydes were minor products.

However, at lower temperatures, as in natural aging conditions, the thermal energy is not sufficient to break $\mathrm{C}-\mathrm{O}$ bonds. Thus, the natural oxidative degradation of PEO is expected to proceed differently. Recent experimental work ${ }^{14,15}$ investigated the thermal degradation of solid state PEO in air at $323 \mathrm{~K}$ and atmospheric pressure. FTIR analysis of the solid residue in the carbonyl region showed that formates and esters were obtained simultaneously and in similar quantities. For comparison, the pho-

* Author to whom correspondence should be addressed. E-mail: pascal.de_sainte-claire@univ-bpclermont.fr. todegradation of solid state PEO in air at $308 \mathrm{~K}$ and atmospheric pressure was performed in an accelerated aging device (SEPAP 14/24) ${ }^{14}$ In that case, $80 \%$ of the carbonyl species were formates, while the remaining $20 \%$ were esters. Degradation products were detected after the induction period, i.e., $\sim 100 \mathrm{~h}$ and $\sim 0.5 \mathrm{~h}$ in thermo-oxidative and photo-oxidative conditions, respectively. These results were independent of molecular weight between 100000 and $4000000 \mathrm{~g} / \mathrm{mol}$. In these experiments, aldehydes were not detected, and the volatile species were not analyzed. This study aims at providing a detailed and quantitative kinetic scheme to explain the above results. First, a series of key competitive reactions is presented on the basis of high-level quantum calculations. When available, the rate constants are picked from the literature. Otherwise, they are computed from the above ab initio data and the canonical transition state theory (CTST). The respective set of differential equations is solved, and the results are compared to experimental work.

\section{Identification of the Degradation Pathway}

A Rapid Survey of the Degradation Mechanism. The aging process is most often assumed to start from a tiny number of reactive polymer radical sites. These radicals may be produced by the abstraction reaction of in-chain hydrogen atoms by molecular oxygen.$^{24}$ However, the influence of the initial quantity of carbon radicals on the rate of polymer degradation was never discussed. It is shown in the Kinetic Model section that a concentration of radical sites as low as $10^{-12} \mathrm{~mol} / \mathrm{cm}^{3}$ is sufficient to initiate the aging process.

The following set of reactions $(\mathrm{I}-\mathrm{V})$ is often proposed in the literature to explain the low-temperature degradation mechanism of PEO in thermo- or photo-oxidative conditions. The degradation starts with the fast addition reaction of molecular oxygen (eq I), followed by intermolecular hydrogen abstraction and formation of the hydroperoxide species (eq II).

Homolytic cleavage of the hydroperoxide can be obtained either thermally or by the faster photoinduced activation (eq III).

Under natural conditions, the troposphere screens wavelengths below $300 \mathrm{~nm}$. Contrary to hydroperoxide species, ${ }^{25}$ peroxy radicals do not absorb UV radiations above this wavelength. ${ }^{26}$ 


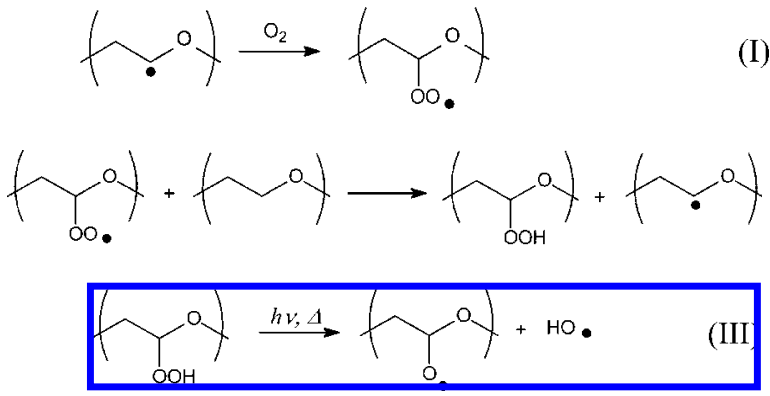

Thus, a mechanism that would include the photodissociation of peroxy radicals and the production of reactive singlet/triplet atomic oxygen ${ }^{27}$ is ruled out under natural aging conditions.

It is generally proposed that $\beta$-scission of alkoxy radicals gives formates

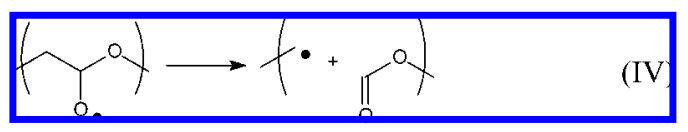

while esters are obtained in radical disproportionation reactions:

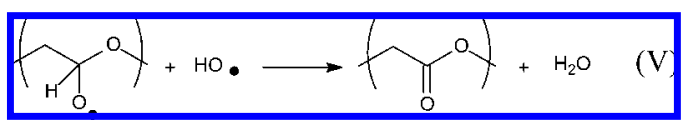

In a recent study ${ }^{13}$ of the degradation of triblock copolymers $\mathrm{PEO}-\mathrm{PPO}-\mathrm{PEO}$, i.e. poly(ethylene oxide-propylene oxideethylene oxide), it is argued that degradation is initiated at PPO blocks because the tertiary hydrogen atom is the most labile. If this PPO H-atom is abstracted by hydroxyl radicals according to eq V, esters are obtained. It is shown in our work that eq $\mathrm{V}$ is not significant for PEO because dissociation of the alkoxy radicals yields formate species extremely rapidly (the respective rate constant calculated in this work is $2 \times 10^{12} \mathrm{~s}^{-1}$ ). However, it is not possible to extract quantitative data from this simple mechanism (eqs $\mathrm{I}-\mathrm{V}$ ). In addition, the termination reaction of peroxy radicals and the bimolecular reaction of two hydroperoxide species may ultimately yield esters and formates as well. However, the probability of these processes was never discussed on a quantitative basis. It is proposed here to build a comprehensive set of elementary reactions that account for the natural degradation of PEO. For example, a recent study of polypropylene degradation showed that intramolecular reactions, however favored by the proximity of reactive sites, are often underestimated with regard to $\beta$-scission reactions. ${ }^{28}$ This type of reaction is carefully investigated in this work. Thus, it is important to explore other pathways in order to address their importance in the degradation mechanism. In this respect, ab initio calculations will prove extremely useful in providing thermodynamic and kinetic evidence for such reactions. This procedure will provide quantitative data for further analysis.

Computational Details. Density functional theory (DFT) calculations were performed with the Gaussian03 suite of programs. $^{29}$ The P86 exchange-correlation functional was chosen because it reproduced accurately bond dissociation energies of second-row species: the real cutoff value of the gradient expansion approximation of the LYP functional is calibrated on the helium atom, a species with zero parallel spin correlation energy, while in the P86 functional, this value was chosen to reproduce the correlation energy of the neon atom where $21 \%$ of the correlation energy arises from parallel spin contributions. ${ }^{30,31}$ This may be at the origin of the discrepancy between the P86 and the LYP functionals for species with second row atoms. The large $6-31++\mathrm{G}(\mathrm{d}, \mathrm{p})$ basis set was chosen to minimize basis set superposition errors. Transition states, geometry optimizations, frequency analyses and energy calculations were performed at the B3P86/6-31++G(d,p) level of theory. Spin-polarized Hamiltonians were used for transition states and open shell species. The reference structure used for the quantum calculations is a 3-mer molecule with methyl endgroups, i.e. $\mathrm{CH}_{3}-\mathrm{O}-\mathrm{CH}_{2}-\mathrm{CH}_{2}-\mathrm{O}-\mathrm{CH}_{2}-\mathrm{CH}_{2}-\mathrm{O}-\mathrm{CH}_{3}$.

Rate constants were computed with the canonical transition state theory:

$$
k_{C T S T}(T)=\frac{k_{B} T}{h} \frac{Q^{\neq}}{Q_{A}} \mathrm{e}^{-E_{0} / R T}
$$

In eq $1, Q_{A}$ and $Q^{\neq}$are the partition functions of the reactant and the transition state, respectively, ${ }^{32}$ for a unimolecular reaction. The energy difference $E_{0}$ between transition state and reactant is corrected for the zero-point energy. $T$ is set at the experimental temperature, i.e. 308 and $323 \mathrm{~K}$ for photo- and thermo-oxidative conditions, respectively. ${ }^{14,15}$ However, our kinetic model is not sensitive to this difference of temperature. Finally, in eq 1, the low frequency modes were not corrected with hindered rotor switching functions. ${ }^{33}$ This point is discussed in the Kinetic Model section.

Oxygen Addition Reaction and Hydroperoxide Formation. As stated before, an infinitesimal fraction of radical sites in the polymer matrix can start the degradation process. These radicals react with excess oxygen according to eq $\mathrm{I}$. The respective addition reaction rate constant is set here at $k_{1}=$ $10^{12} \mathrm{~cm}^{3} \mathrm{~mol}^{-1} \mathrm{~s}^{-1} \cdot 34,35$ Stationary concentration of oxygen is assumed. However, the oxygen equilibrium concentration might be different in amorphous or crystalline regions of the polymer because $\mathrm{O}_{2}$ diffuses more easily in unordered medium. ${ }^{36}$ In addition, the oxygen concentration is expected to decrease with sample thickness. If low levels of oxygen are reached inside the polymer sample, the hypothesis of $\mathrm{O}_{2}$ stationary state might not hold true. In this case, radical species might rather react in termination reactions. However, for the typical equilibrium oxygen concentrations found in outermost regions of polymers exposed to air, it is shown in the last section (for PEO) that radical terminations are less probable than oxygen addition reactions. In addition, our results are not sensitive to the oxygen concentration (see last section).

Hydrogen abstraction from adjacent polymer chains (intermolecular mechanism) yields the hydroperoxide species (eq II). The respective rate constant per hydrogen atom and activation energy were shown to be linearly dependent on the $\mathrm{R}-\mathrm{H}$ bond strength: $\log \left(k_{2}\right)=16.4-0.2 \times \Delta H^{\circ}$ and $E_{a}=0.55 \times\left(\Delta H^{\circ}\right.$ - 62.5) were found for secondary peroxy radicals and a temperature of $303 \mathrm{~K}^{37}$ Provided the Arrhenius prefactor and $E_{a}$ are independent of $T, k_{2}$ can be obtained for any temperature from these relationships. The $\mathrm{PEO}-\mathrm{H}$ bond dissociation energy is $D^{\circ}(\mathrm{PEO}-\mathrm{H})=95.7 \mathrm{kcal} / \mathrm{mol}$ at the UB3P86/6-31++ $\mathrm{G}(\mathrm{d}, \mathrm{p})$ level, while it is $D^{\circ}\left(\mathrm{CH}_{3} \mathrm{OCH}_{2}-\mathrm{H}\right)=96.4 \mathrm{kcal} / \mathrm{mol}$ at the same level of theory. Considering the $\mathrm{C}-\mathrm{H}$ bond strength in $\mathrm{PEO}$ and dimethyl ether (DME) are similar, it is justified to use the experimental hydrogen abstraction rate constant of DME for PEO. With these results and the above equations, ${ }^{38}$ the temperature dependent rate constants $k_{2}(308 \mathrm{~K})=24.2 \mathrm{~cm}^{3} \mathrm{~mol}^{-1}$ $\mathrm{s}^{-1}$ and $k_{2}(323 \mathrm{~K})=79.5 \mathrm{~cm}^{3} \mathrm{~mol}^{-1} \mathrm{~s}^{-1}$ were obtained.

However, for low temperatures, as in natural oxidative conditions, the mobility of the polymer is restricted. Thus, in addition to the above intermolecular mechanism, other reactive pathways, especially those involving intramolecular reactions, are likely to occur. Three types of hydrogen atoms, further labeled $\alpha, \beta$ and $\gamma$ can be abstracted intramolecularly by the peroxy radical (Figure 1). The respective 4-, 5- and 6-ring transition states were characterized at the UB3P86/6-31++G(d,p) level (see Figure 2). Abstraction of a hydrogen atom in the $\alpha$ 


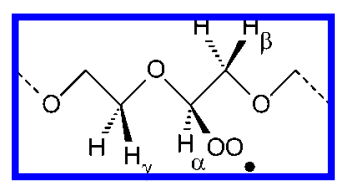

Figure 1. Peroxy radical intramolecular abstraction reaction. Reactive hydrogen atoms are labeled $\alpha, \beta$, and $\gamma$, according to their position with respect to the peroxy group.

position leads to a radical species that dissociates on the microsecond time scale $22,39,40$ into a long-range complex between the hydroxyl radical and the ester species through hydrogen bonding interactions. However, $\mathrm{TS}_{\alpha}$ is fairly high (see Figure 2) and the respective calculated rate constant is small. Thus, such a process can be ruled out on kinetic grounds. Comparison of the rate constants for the remaining $\beta$ - and $\gamma$-hydrogen abstraction reactions shows that the $\gamma$-forward and reverse pathways are significantly favored. Similar rate constants were reported for linear hydrocarbons. ${ }^{41}$ In conclusion, the $\beta$-pathway is not included in our kinetic model. Since the $\gamma$-intramolecular reaction is endothermic (see Figure 2), the reverse reaction retards significantly the formation of the hydroperoxide species. However, the rapid addition reaction of molecular oxygen $\left(k_{1}=10^{12} \mathrm{~cm}^{3} \mathrm{~mol}^{-1} \mathrm{~s}^{-1}\right)$ stabilizes a fraction of the product radicals and allows propagation of the degradation mechanism.

Additional UB3P86/6-31++G(d,p) calculations were performed to obtain the intermolecular $\mathrm{H}$-abstraction reaction energy (eq II). $\Delta_{r} H^{\circ}=+14.7 \mathrm{kcal} / \mathrm{mol}$ was found, a value which is similar to that of the $\gamma$-intramolecular path (see Figure 2). Thus, competition between $\gamma$-intramolecular and intermolecular hydrogen abstraction is likely to occur (eq VI).

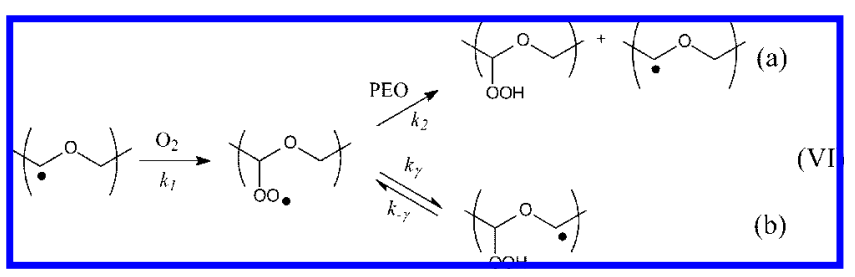

Hydroperoxide Decomposition. Thermal Dissociation of Hydroperoxides. In thermo-oxidative conditions, hydroperoxide species decompose mainly according to

$$
\begin{gathered}
\mathrm{POOH} \rightarrow \mathrm{PO}^{\bullet}+{ }^{\bullet} \mathrm{OH} \\
\mathrm{POOH}+\mathrm{PH} \rightarrow \mathrm{PO}^{\bullet}+\mathrm{P}^{\bullet}+\mathrm{H}_{2} \mathrm{O} \\
\mathrm{POOH}+\mathrm{POOH} \rightarrow \mathrm{PO}^{\bullet}+\mathrm{POO}^{\bullet}+\mathrm{H}_{2} \mathrm{O}
\end{gathered}
$$

Pathway a is the true monomolecular dissociation and proceeds with large activation energy. The rate constant for hydroperoxide dissociation is generally larger in reactions $b$ and $\mathrm{c}$ because activation energies are smaller than the $\mathrm{PO}-\mathrm{OH}$ bond dissociation energy. ${ }^{24,42-44}$ Provided $[\mathrm{PH}] \gg[\mathrm{POOH}]$, path $b$ can be described by pseudo monomolecular kinetics. Pathway $\mathrm{c}$ is the preferred path when the concentration of hydroperoxides is significant. This may be the case locally in specific heterogeneous condensed media at early stages of initiation steps. However, these local effects disappear rapidly as the degradation process continues; in that case, hydroperoxide decomposition is expected to follow pseudo monomolecular kinetics. ${ }^{45}$

The thermal unimolecular dissociation rate constant (process a) of tert-butyl hydroperoxide is $k_{a}\left(\mathrm{~s}^{-1}\right)=6.31 \times 10^{15} \exp (-43 /$ $R T) .{ }^{46}$ The activation energy $(\mathrm{kcal} / \mathrm{mol})$ in this case is representative of $\mathrm{RO}-\mathrm{OH}$ bond strengths. For example, the hydroperoxide electronic bond dissociation energy in PEO is 44.4 $\mathrm{kcal} / \mathrm{mol}$ at the UB3P86/6-31++G(d,p) level of theory when the most covalent structure of the alkoxy radical species is considered (see discussion below and species $a$ in Figure 3). This relationship yields $k_{a}(323 \mathrm{~K})=8 \times 10^{-10} \mathrm{~s}^{-1}$ which is representative for this type of reaction. Processes b and $\mathrm{c}$, however, proceed with lower activation energies (20-30 kcal/ $\mathrm{mol}){ }^{24,47-50} \mathrm{In}$ addition, the thermal decomposition of hydroperoxides in the solid phase follows apparent first-order kinetics. This was described as a consequence of heterogeneity in the medium and reflects the reaction of hydroperoxide pairs that are distributed evenly in specific elementary oxidation volumes. ${ }^{51}$ While numerous studies investigated the bimolecular decomposition of hydroperoxides at relatively high temperatures $(T>373 \mathrm{~K})$, Gijsman et al. ${ }^{52}$ report the respective low temperature oxidation rate constant of polypropylene. Their results show that restricted mobility of molecules in the polymer may explain the discrepancies between low and high temperature degradation mechanisms. In their work, the apparent experimental first-order rate constant for the bimolecular hydroperoxide decomposition is $k_{3}(323 \mathrm{~K})=3.8 \times 10^{-8} \mathrm{~s}^{-1},{ }^{53}$ a value that is lower than that obtained from extrapolation of higher temperature experiments. ${ }^{24,50}$ The respective activation energy is $22.4 \mathrm{kcal} / \mathrm{mol}$, a value which is representative of the bimolecular decomposition mechanism. Thus, for many polymers in thermo-oxidative conditions, the apparent first-order bimolecular decomposition rate constant is larger than that of the unimolecular dissociation. However, this is no longer true when the hydroperoxide $\mathrm{RO}-\mathrm{OH}$ bond strength is smaller than usual because of specific electronic effects. In this case, the unimolecular dissociation rate constant may become larger than $k_{3}$, the bimolecular hydroperoxide decomposition rate constant. Thus hydroxyl radicals are released in the medium and, provided the concentration of $\mathrm{HO}^{\circ}$ is sufficient, the induced decomposition reaction (eq VII) competes with the unimolecular dissociation mechanism.

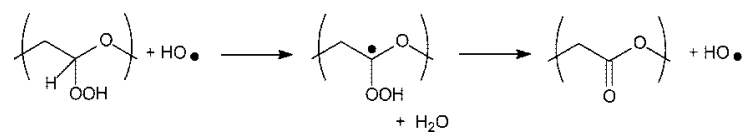

In eq VII, the lifetime of the intermediate species is believed to be smaller than $20 \mu \mathrm{s}$. $^{22,39,40}$

In our simulations, the maximum concentration of hydroxyl radicals in thermo-oxidative conditions is $\sim 3 \times 10^{-20} \mathrm{~mol} / \mathrm{cm}^{3}$. If the respective bimolecular rate constant in eq VII is $1.4 \times$ $10^{13} \mathrm{~cm}^{3} \mathrm{~mol}^{-1} \mathrm{~s}^{-1}$ (see discussion later in this paper), this process becomes competitive with the unimolecular dissociation mechanism $\left(k_{d}(323 \mathrm{~K})=6.4 \times 10^{-8} \mathrm{~s}^{-1}\right.$; see below $)$. In fact, when eq VII is removed from our kinetic model, the ester concentration drops significantly.

Electronic structure calculations reveal that the $\mathrm{RO}-\mathrm{OH}$ bond strength in PEO is smaller than usual. The unimolecular dissociation of PEO (PEO-OOH $\rightarrow$ PEO- $\left.\mathrm{O}^{\bullet}+{ }^{\circ} \mathrm{OH}\right)$ was investigated at the UB3P86/6-31++G(d,p) level. Two minimum structures were obtained for $\mathrm{PEO}-\mathrm{O}^{\circ}$. These are described in Figure 3 . The most covalent geometry is $4.4 \mathrm{kcal} / \mathrm{mol}$ above the most stable, less covalent species. The latter is stabilized by short-range hydrogen bonding, thus enhancing electron withdrawing from the carbon/carbon bond in the $\alpha$ position of the alkoxy group. If the unimolecular hydroperoxide dissociation yields the low-energy species, the actual respective enthalpy of reaction is considerably lowered. $\Delta H^{\circ}(323 \mathrm{~K})=35.5 \mathrm{kcal} / \mathrm{mol}$ was computed at the DFT level. Similar values are reported in the literature for the unimolecular decomposition of paraffin hydroperoxides: $\log \left(k_{d}\right)=15.2-33.1 / 2.3 R T$ was reported for Exxsol D-80, ${ }^{49}$ i.e. $k_{d}(323 \mathrm{~K})=6.4 \times 10^{-8} \mathrm{~s}^{-1}$. The prefactor in this expression is similar to that of the unimolecular reaction 


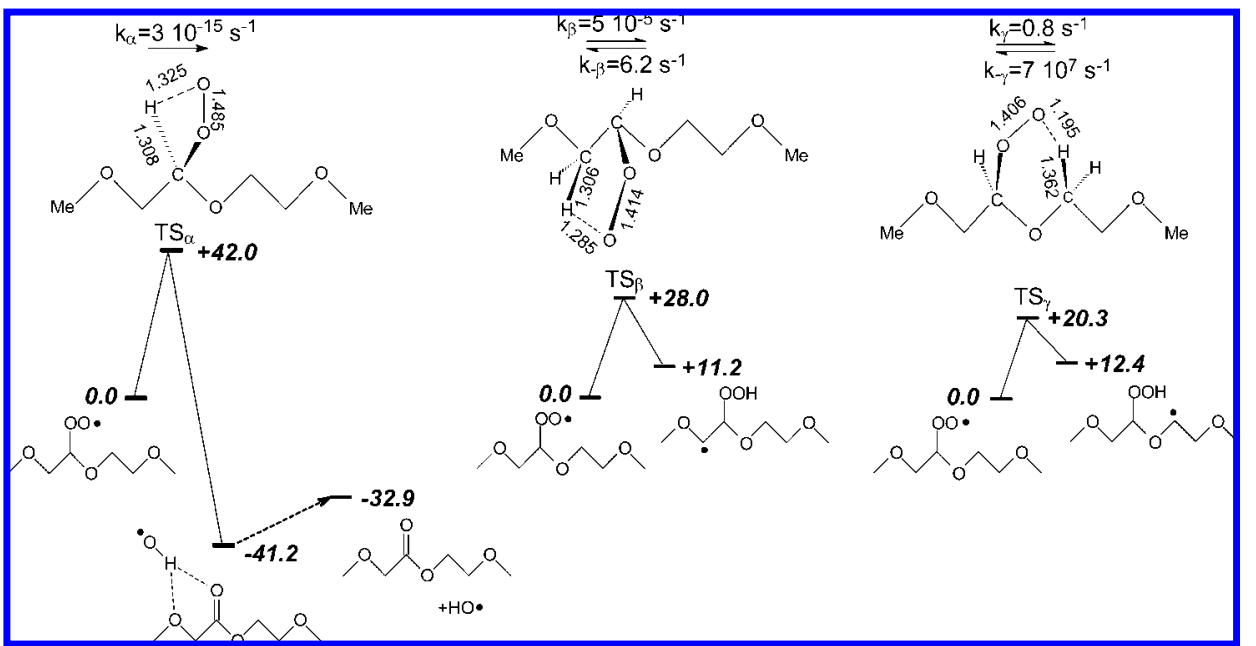

Figure 2. UB3P86/6-31++G(d,p) electronic energy levels, transition structures and CTST rate constants for the intramolecular peroxy radical abstraction reactions of $\alpha, \beta$, and $\gamma$ hydrogen atoms (see Figure 1). Bond lengths in $\AA$, energies in $\mathrm{kcal} / \mathrm{mol}$. The rate constants on this figure are computed for $T=308 \mathrm{~K} . k_{\gamma}=2.8 \mathrm{~s}^{-1}$ and $k_{-\gamma}=1.0 \times 10^{8} \mathrm{~s}^{-1}$ for $T=323 \mathrm{~K}$.

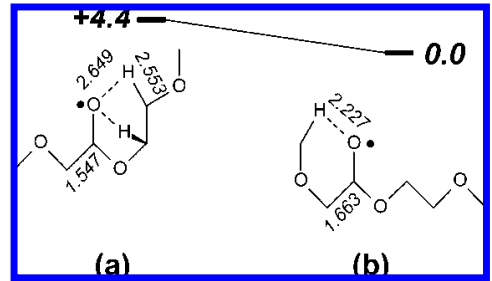

Figure 3. Minimum structures obtained for the alkoxy radical at the UB3P86/6-31++G(d,p) level of theory. Structure $b$ is the less covalent, most stable geometry. Energies in kcal/mol; bond lengths in $\AA$.

rate constants investigated in our work. Thus, for PEO, the unimolecular dissociation pathway is the main hydroperoxide decomposition process. Nevertheless, the bimolecular hydroperoxide dissociation was included in our kinetic model $\left(k_{3}\right)$ for sensitivity analysis purposes.

Photoinduced Dissociation of Hydroperoxides. In natural aging conditions $(\lambda>300 \mathrm{~nm})$, absorbing species include hydroperoxide and carbonyl groups; although the former is not as strong an absorber, it bears the most significant role in the degradation process. The experimental temperature of $308 \mathrm{~K}$ is used here for rate constant calculations. ${ }^{14,15}$ The photodissociation of the $\mathrm{O}-\mathrm{O}$ hydroperoxide bond proceeds with unity quantum yield. ${ }^{39}$ Alkoxy and hydroxyl radicals are obtained.

The photodissociation of methyl hydroperoxide (MHP) was investigated in a recent study. ${ }^{54}$ In this work, the radiation source was chosen to reproduce the natural UV spectrum at earth ground level. Under these conditions and $T=289 \mathrm{~K}$, the MHP photolysis frequency was $j=4.5 \times 10^{-5} \mathrm{~s}^{-1}$. In comparison, the experimental photodegradation of PEO was conducted in SEPAP 14/24, ${ }^{14,15}$ a device that accelerates the natural aging process of aliphatic polymers by a factor of $\sim 10$. Thus, the photolysis frequency in SEPAP $14 / 24$ is larger than $4.5 \times 10^{-5} \mathrm{~s}^{-1}$. Our model reproduced accurately the induction time of the photodegradation of PEO in SEPAP $14 / 24$ if $j=4.5 \times 10^{-4} \mathrm{~s}^{-1}$. The sensitivity analysis of our kinetic model with respect to several rate constants, including $j$, is presented in the final section.

Under photo-oxidative conditions, the maximum hydroxyl radical concentration is $3 \times 10^{-18} \mathrm{~mol} / \mathrm{cm}^{3}$. Thus, the induced hydroperoxide dissociation (eq VII) can be neglected under these conditions with respect to the unimolecular hydroperoxide dissociation.

Other Hydroperoxide Dissociation Pathways. In addition, other reactive pathways are available to the open-shell hydroperoxide obtained in eq VIb (intramolecular $\gamma$-hydrogen abstraction path). First, aldehydes are obtained in $\beta$-scission reactions:

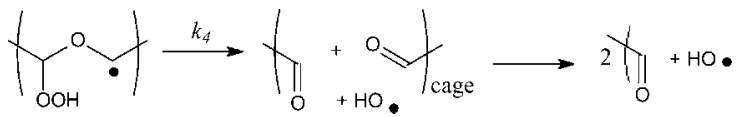

Alternatively, alkoxy radicals may be obtained through intramolecular $\mathrm{OH}$ shift:

$$
X_{\mathrm{OOH}}^{\mathrm{O}} Y \stackrel{k_{4}^{\prime}}{\longrightarrow} X_{\mathrm{O}}^{\mathrm{O}} \mathrm{Y}_{\mathrm{OH}}
$$

These reactions are described in Figure 4. The unimolecular dissociation of the open-shell hydroperoxide was not included in our kinetic model because $k_{4} \gg j, k_{d}$. Analysis of the respective rate constants (eqs VIII and IX) shows that the aldehyde pathway is favored. Thus, reaction IX was not included in our model. Note that $\mathrm{TS}_{4}$ is connected with a long-range complex where the fragments (aldehydes and hydroxyl radical) are stabilized through hydrogen bonding interactions. The complete dissociation of this complex was not included in our model. However, it is shown in the last section that aldehydes are minor products in the degradation process.

Finally, eq VIII may compete with the addition reaction of molecular oxygen:

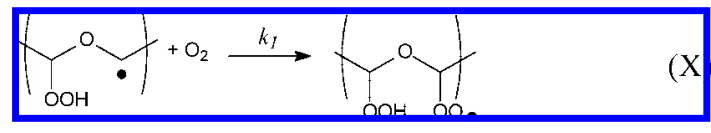

The product in eq $\mathrm{X}$ can react in intermolecular $\mathrm{H}$-abstraction reactions and yield a species with adjacent hydroperoxide groups:

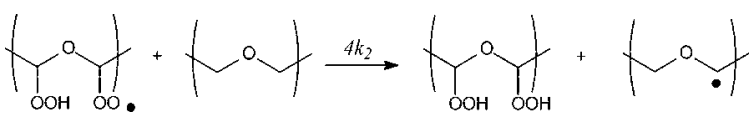

The peroxy radical can also abstract intramolecularly $\beta$ - and $\gamma$-hydrogen atoms (see Figure 1). $\mathrm{TS}_{\beta}$ was found $28 \mathrm{kcal} / \mathrm{mol}$ above the reactant (see Figure 2). However, $k_{\beta} / 4 k_{2}=0.9 \times$ $10^{-6} \mathrm{~mol} / \mathrm{cm}^{3}$ at $323 \mathrm{~K}$, and $k_{\beta}$ becomes competitive over the intermolecular reaction only when the concentration of unreacted 1 -mer units drops below $\sim 10^{-6} \mathrm{~mol} / \mathrm{cm}^{3}$. Nevertheless, when such concentration levels are reached, most available in-chain $\mathrm{H}$-atoms have already been replaced by hydroperoxide groups. Thus, these reactions do not contribute significantly to the overall mechanism and intramolecular propagation was stopped at the 


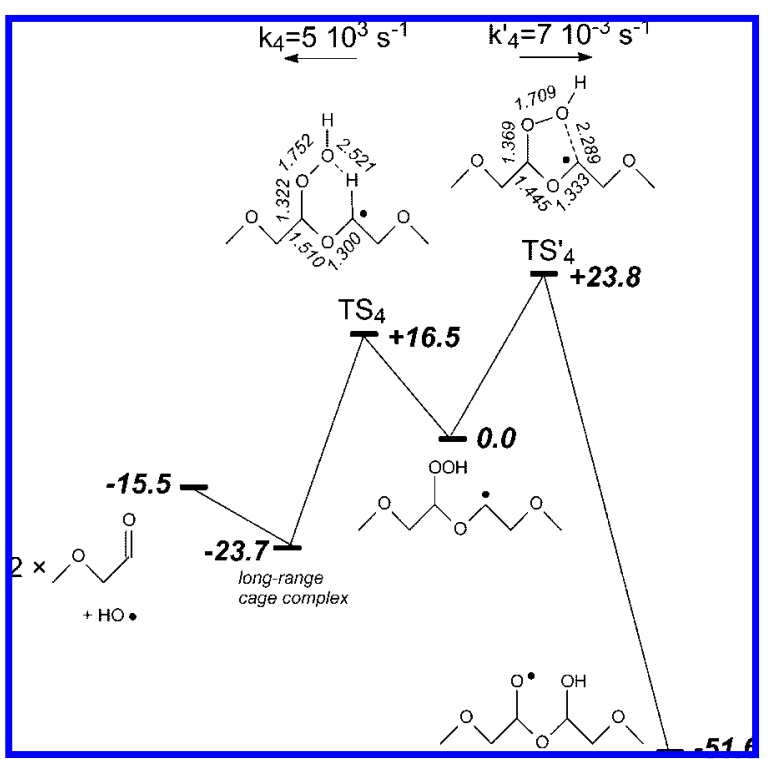

Figure 4. Same as Figure 2 for reactions VIII and IX. The rate constants on this figure are computed for $T=308 \mathrm{~K} . k_{4}=1.5 \times 10^{4} \mathrm{~s}^{-1}$ and $k_{4}^{\prime}$ $=3.8 \times 10^{-2} \mathrm{~s}^{-1}$ were obtained for $T=323 \mathrm{~K}$. The geometry of the hydroperoxide open-shell species on this figure is slightly different whether connected to $\mathrm{TS}_{4}$ or $\mathrm{TS}_{4}{ }_{4}$. In the latter, rotation about a $\mathrm{C}-\mathrm{O}$ bond stabilizes $(4 \mathrm{kcal} / \mathrm{mol})$ the hydroperoxide $\mathrm{H}$-atom through $\mathrm{ROOH}----\mathrm{O}$ van der Waals bonding. Energies are relative to the respective reactant structure.

hydroperoxide dimer in our simulations. Consequently, the $\beta$-intramolecular abstraction pathway was not included in the model. Finally, longer sequences of hydroperoxides can be obtained if series of consecutive mer-units bear adjacent hydroperoxide groups.

The $\gamma$-intramolecular $\mathrm{H}$-abstraction pathway was investigated at the DFT level (eq XII).

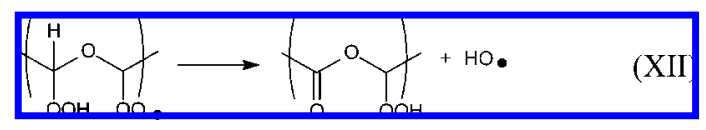

The transition state in this reaction was $45.0 \mathrm{kcal} / \mathrm{mol}$ above the reactant. Thus, these channels $(\beta$ - or $\gamma$-) do not compete with the intermolecular $\mathrm{H}$-abstraction pathway.

In eq XI, a species with adjacent hydroperoxide groups is obtained. It was found here that intramolecular decomposition of neighboring hydroperoxide groups $(\mathrm{RCOOH}-\mathrm{O}-\mathrm{COOH}-\mathrm{R}$ $\left.\rightarrow \mathrm{RCO}^{\circ}-\mathrm{O}-\mathrm{COO}^{\circ}-\mathrm{R}+\mathrm{H}_{2} \mathrm{O}\right)$ is strongly endothermic and cannot compete with the unimolecular dissociation pathway.

The bimolecular dissociation of adjacent hydroperoxides in PEO was further investigated at the UB3P86/6-31++G(d,p) level (see eq XIII).

$$
\left(\mathrm{OOH}_{\mathrm{OOH}}^{\mathrm{O}} \longrightarrow X_{\mathrm{OOH}}^{\mathrm{O}} \prod_{\mathrm{O}}+\mathrm{H}_{2} \mathrm{O}\right.
$$

This reaction is made of two consecutive exothermic reactions (see Figure 5). The intermediate structure undergoes a hydrogen shift reaction and yields a species with both hydroperoxide and ester groups. However, the first transition state $\mathrm{TS}_{b-a d j}$ in Figure 5 is $43.1 \mathrm{kcal} / \mathrm{mol}$ above the reactant and the respective decomposition rate constant $k_{b-a d j}(323 \mathrm{~K})=1.4 \times 10^{-14} \mathrm{~s}^{-1}$ is not competitive with the unimolecular hydroperoxide dissociation rate constant $\left(j, k_{d}\right)$.

Last, Decker and Marchal ${ }^{55}$ proposed that esters could be obtained in a concerted reaction that involves a 6-ring transition state as described in eq XIV below:

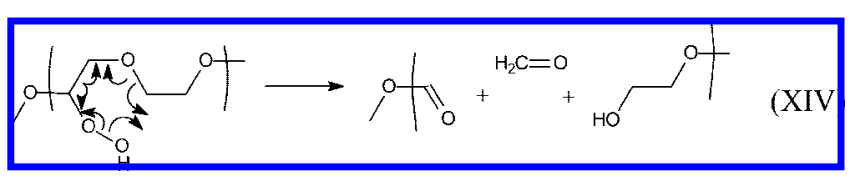

This reaction was investigated at the above DFT level. It was found that eq XIV is best described by a two-step mechanism that involves the formation of a peroxide species (see Figure 6). The first transition state is $77.5 \mathrm{kcal} / \mathrm{mol}$ above the reactant. Thus, this reaction is not significant in the general degradation mechanism. Note that the products in eq XIV are yielded in this work as well, although these species are obtained here through lower energy channels.

Alkoxy, Hydroxyl, and Peroxy Radical Reactions. Alkoxy Radicals. The unimolecular decomposition of alkoxy radicals was investigated by ab initio calculations at the UB3P86/6-31++G(d,p) level of theory (Figure 7). As stated before, two local minima were found for the alkoxy radical (see Figure 3). In the low-energy structure, the carbon/carbon bond in the $\alpha$ position of the alkoxy radical is elongated (1.66 $\AA$ ). This predissociative structure undergoes rapid $\beta$-scission and yields the formate species. The forward and backward CTST rate constants $k_{5}$ and $k_{-5}$ were calculated from the thermodynamic properties of the transition state $\mathrm{TS}_{5}$, the reactant and products. However, the backward rate constant $k_{-5}$ was not included in our kinetic simulation because the reaction of primary radicals with excess molecular oxygen proceeds rapidly $\left(k_{1} \times\left[\mathrm{O}_{2}\right] \gg\right.$ $k_{-5} \times$ [formate]). Last, the reaction of hydroxyl radicals with secondary alkoxy species was not included in the model because the $\beta$-scissions are strongly favored.

The reactivity of primary alkoxy end-radicals needs to be treated separately because the $\beta$-scission pathway is not available to this species. In addition, the formaldehyde pathway $\left(\mathrm{ROCH}_{2} \mathrm{O}^{\circ} \rightarrow \mathrm{RO}^{\circ}\right.$ $\left.+\mathrm{H}_{2} \mathrm{CO}\right)$ is strongly endothermic $(17.9 \mathrm{kcal} / \mathrm{mol}$ at the UB3P86/ $6-31++\mathrm{G}(\mathrm{d}, \mathrm{p})$ level). Thus, in our model, primary alkoxy radicals react in intermolecular $\mathrm{H}$-abstraction reactions.

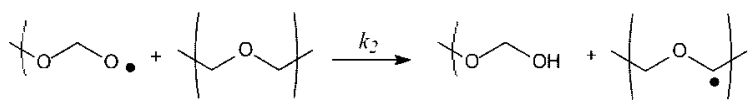

Alternatively, primary alkoxy radicals can react with $\mathrm{HO}^{\circ}$ and yield formates in radical disproportionation reactions similar to eq $\mathrm{V}$. In thermo-oxidative conditions, a small amount of alkoxy radicals remains unreacted at the end of the simulation and thus can dissociate according to the above formaldehyde pathway.

Hydroxyl Radicals. Other important reactions include hydrogen abstraction by hydroxyl radicals (eq XVIa below). This rate constant was measured for several ether molecules: $k_{\mathrm{Me}_{2} \mathrm{O}}=1.8$ $\times 10^{12} \mathrm{~cm}^{3} \mathrm{~mol}^{-1} \mathrm{~s}^{-1}$ and $k_{\left[\mathrm{CH}_{3}\left(\mathrm{CH}_{2}\right)_{3}\right]_{2} \mathrm{O}}=1.6 \times 10^{13} \mathrm{~cm}^{3} \mathrm{~mol}^{-1}$ $\mathrm{s}^{-1}$ were found for dimethyl ether and di- $n$-butyl ether respectively, at $308 \mathrm{~K}^{56}$ The rate constant per secondary hydrogen atom was deduced by removing the contribution of primary

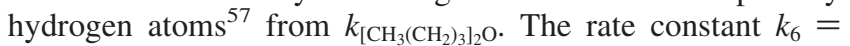
$\left(k_{\left[\mathrm{CH}_{3}\left(\mathrm{CH}_{2}\right)_{3}\right]_{2} \mathrm{O}}-k_{\mathrm{Me}_{2} \mathrm{O}}\right) / 12=1.2 \times 10^{12} \mathrm{~cm}^{3} \mathrm{~mol}^{-1} \mathrm{~s}^{-1}$ was obtained at $308 \mathrm{~K}\left(k_{6}=1.1 \times 10^{12} \mathrm{~cm}^{3} \mathrm{~mol}^{-1} \mathrm{~s}^{-1}\right.$ at $\left.323 \mathrm{~K}\right)$. In addition, the radical disproportionation and the hydrogen abstraction reactions $b_{1}$ and $b_{2}$ in eq XVI, respectively, were shown to bear significant importance. ${ }^{22,39}$ However the respective branching ratio $k_{7}^{\prime} / k_{7}$ is still the subject of controversy.

The existence of a radical intermediate in reaction $b_{1}$ is often postulated (see also eq VII). However, such a structure could not be detected on the UB3P86/6-31++G(d,p) potential energy surface, in agreement with another study. ${ }^{40}$

The rate constants $k_{7}$ and $k_{7}^{\prime}$ were determined from experimental data and ab initio calculations. The bimolecular reaction of hydroxyl radicals with methyl hydroperoxide was studied 


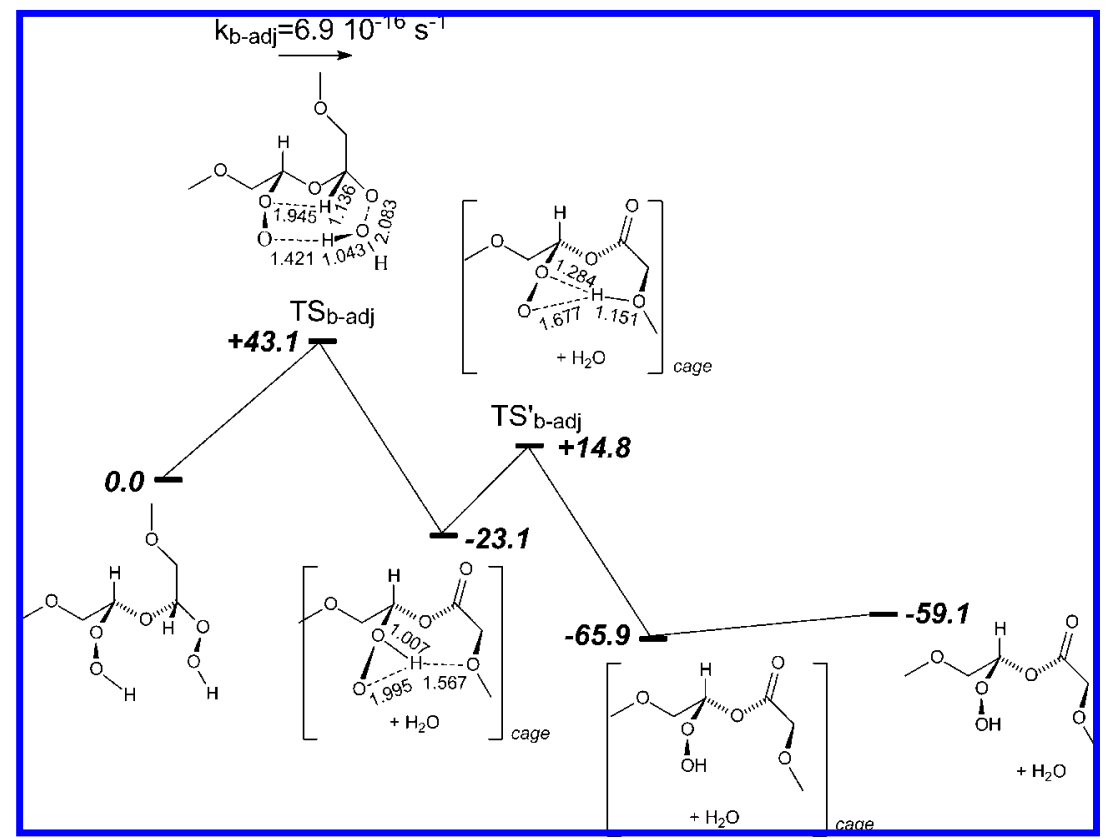

Figure 5. Intramolecular dissociation of adjacent hydroperoxide groups. Calculations were performed at the UB3P86/6-31++G(d,p) level. Bond lengths in $\AA$; energies in $\mathrm{kcal} / \mathrm{mol}$. The rate constant in this figure is computed for $T=308 \mathrm{~K} . k_{b-a d j}(323 \mathrm{~K})=1.4 \times 10^{-14} \mathrm{~s}^{-1}$.

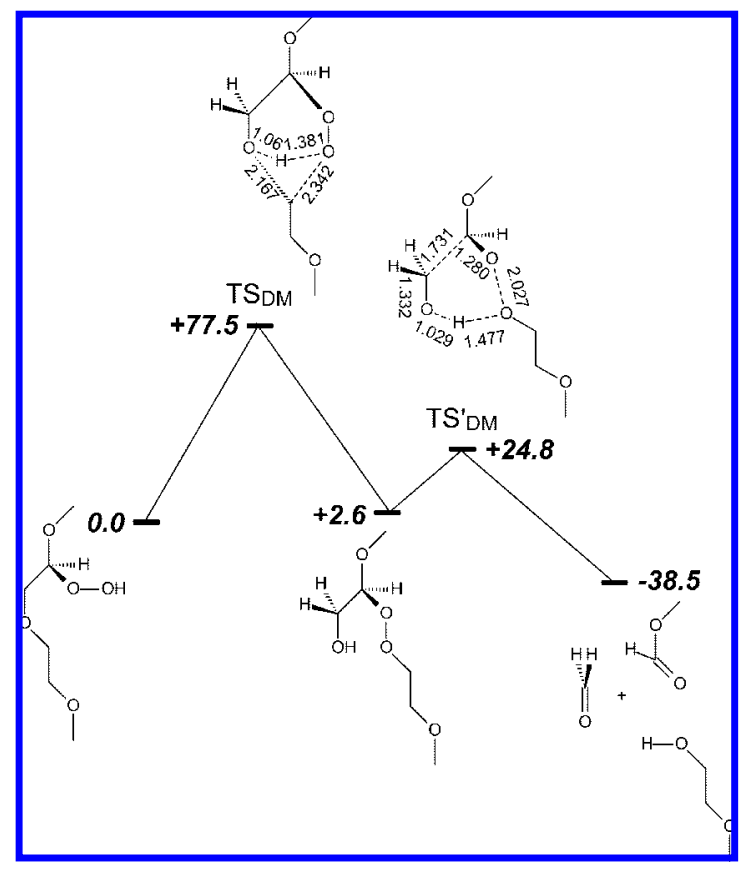

Figure 6. Investigation of the Decker and Marchal mechanism ${ }^{55}$ at the UB3P86/6-31++G(d,p) level. Energies in kcal/mol; bond lengths in $\AA$.

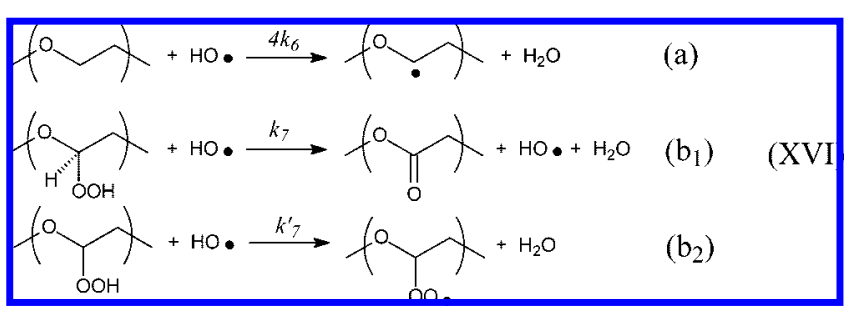

by laser induced fluorescence techniques. ${ }^{22,39}$ The rate constant for the peroxy radical channel $\left(\mathrm{CH}_{3} \mathrm{OOH}+\mathrm{HO}^{\bullet} \rightarrow \mathrm{CH}_{3} \mathrm{OO} \cdot\right.$ $\left.+\mathrm{H}_{2} \mathrm{O}\right)$ ranged between 2.3 and $5.4 \times 10^{12} \mathrm{~cm}^{3} \mathrm{~mol}^{-1} \mathrm{~s}^{-1}$. The overall ratio of the rate constants for the peroxy radical channel and the aldehyde channel $\left(\mathrm{CH}_{3} \mathrm{OOH}+\mathrm{HO}^{\circ} \rightarrow \mathrm{H}_{2} \mathrm{CO}\right.$ $+\mathrm{HO}^{\circ}+\mathrm{H}_{2} \mathrm{O}$ ) ranged between $1.3^{58}$ and 2.5. ${ }^{22}$ However, our kinetic model is slightly sensitive to the ratio $k_{7}^{\prime} / k_{7}$ in thermo-

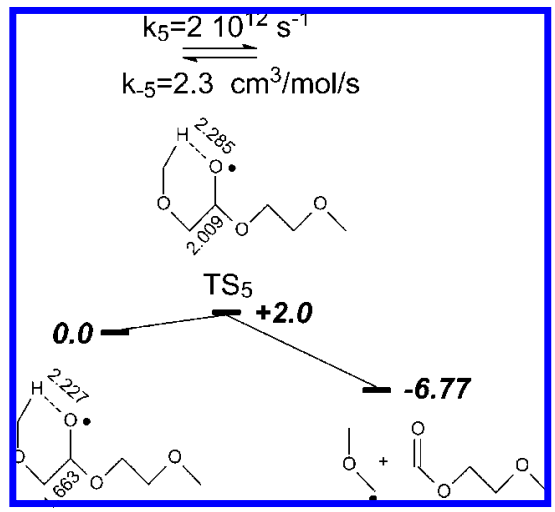

Figure 7. Same as Figure 2 for the dissociation of the alkoxy radical into formate (eq IV). Forward and backward CTST rate constants on this figure are calculated for a temperature of $308 \mathrm{~K}$. $k_{5}$ is similar for $T=323 \mathrm{~K}$.

oxidative conditions (see Kinetic Model section). Additional calculations were performed at the UB3P86/6-31++G(d,p) level to compute the ROO- $\mathrm{H}$ bond strength in $\mathrm{CH}_{3} \mathrm{COO}-\mathrm{H}$ and (PEO)OO-H. Similar values $(89.1$ and $90.2 \mathrm{kcal} / \mathrm{mol}$, respectively) were found. In addition, the electronic reaction energy of the peroxy radical channel (eq XVI b2) was similar for both species (36.5 and $36.4 \mathrm{kcal} / \mathrm{mol}$, respectively). Thus $k_{7}^{\prime}$, in our work, was set at the most recent experimental value ${ }^{39}$ for methyl hydroperoxide, i.e. $k_{7}^{\prime}=5.4 \times 10^{12} \mathrm{~cm}^{3} \mathrm{~mol}^{-1} \mathrm{~s}^{-1}$. This rate constant is nearly independent of temperature in the range considered here. The sensitivity of our model with respect to this parameter is examined in the final section. The magnitude of $k_{7}$ (ester channel, eq XVI b1) is discussed now. Two independent studies ${ }^{22,58}$ of the methyl hydroperoxide reaction with hydroxyl radicals report different branching ratios $k_{7}^{\prime} / k_{7}$. Considering rate constants per abstractable hydrogen atom, the most recent value for this ratio is $7.5 .^{22}$ However, in PEO, significant enhancement is expected for $k_{7}$ because the labile hydrogen atom is in a tertiary position (primary in $\mathrm{CH}_{3} \mathrm{COOH}$ ). The rate constant for the $\mathrm{H}$-atom abstraction reaction by hydroxyl radicals is enhanced by a factor of 10-30 between primary and tertiary sites. ${ }^{59-61}$ Thus, $k_{7}^{\prime} / k_{7}$ is expected to range between 0.25 and 0.75 . 
Finally, the reaction of $\mathrm{HO}^{\circ}$ with $\mathrm{H}$-atoms in the $\alpha$-position of secondary alkoxy radicals (eq V) was not included here because the dissociation to the formate species is strongly favored.

Termination Reaction of Peroxy Radicals: The Tetroxide Pathway. The reactivity of peroxy radicals is investigated for the termination reaction. At low concentrations, the peroxy species react in $\mathrm{H}$-abstraction reactions (eq VI). However, when the concentration of peroxy radicals becomes significant, $k_{2}$ and $k_{\gamma}$ compete with the peroxy radical termination reaction (eq XVII): ${ }^{62,63}$

$$
\mathrm{ROO}^{\bullet}+\mathrm{OOOR}^{\prime} \stackrel{k_{8}^{0}}{\rightarrow} \mathrm{RO}_{4} \mathrm{R}^{\prime}
$$

(XVII)

In eq XVII, the reactants are secondary or tertiary peroxy radicals, whether obtained from end-radicals or in-chain polymer radicals. Experimental values for $k_{8}^{0}$ range between $10^{9}-10^{10}$ $\mathrm{cm}^{3} \mathrm{~mol}^{-1} \mathrm{~s}^{-1}$ for the self-reaction of secondary peroxy radicals. ${ }^{26,34}$ This rate constant is larger for primary radicals, and is enhanced for ether oxides. For example, $k_{8}^{0}$ is $10^{12} \mathrm{~cm}^{3}$ $\mathrm{mol}^{-1} \mathrm{~s}^{-1}$ for the self-reaction of $\mathrm{CH}_{3} \mathrm{OCH}_{2} \mathrm{OO}$ at $298 \mathrm{~K}$ and atmospheric pressure. ${ }^{26,64}$ These differences reflect changes in the activation energy of the backward tetroxide dissociation. High activation energy, e.g. for the decomposition of secondary tetroxide species, means there is significant backward reaction $\left(\mathrm{RO}_{4} \mathrm{R}^{\prime} \rightarrow \mathrm{ROO}^{\circ}+{ }^{\circ} \mathrm{OOR}^{\prime}\right)$. In our model, the backward reaction is intrinsic in $k_{8}^{0}$. Rate constants for the termination reaction of secondary and primary peroxy radicals are set here to $10^{10}$ and $10^{12} \mathrm{~cm}^{3} \mathrm{~mol}^{-1} \mathrm{~s}^{-1}$, respectively. It is $10^{11} \mathrm{~cm}^{3} \mathrm{~mol}^{-1} \mathrm{~s}^{-1}$ for the mixed reaction of a secondary and a primary peroxy radical.

However, $k_{8}$ is diffusion-controlled and depends on polymer chain length. Simplification of the Smoluchowski's equation ${ }^{65,66}$ yields $k_{8}(t)=k_{8}^{0} / n^{i}(t)$ where $i=1$ below the entanglement limit $\left(N_{e}=50\right.$ for $\left.\mathrm{PEO}^{67}\right)$, and $i=2$ otherwise. Continuous variation of $i$ is ensured through the use of a switching function. In this equation, $n(t)$ is the average chain length at time $t$. Considering one bond scission yields one formate species, $n(t)$ can be obtained from the concentration of formates $[F]$, the initial quantity of mer units $[\mathrm{M}]_{0}$, and the initial mean chain length, $n_{0}{ }^{68}$

$$
n(t)=1 /\left([F] /[M]_{0}+1 / n_{0}\right)
$$

Finally, the tetroxide dissociation can yield alkoxy radicals: ${ }^{26,34}$

$$
\mathrm{RO}_{4} \mathrm{R}^{\prime} \stackrel{k_{9}}{\rightarrow} \mathrm{RO}^{\bullet}+\mathrm{O}_{2}+{ }^{\circ} \mathrm{OR}^{\prime}
$$

Alternatively, ester and alcohol species may be obtained. ${ }^{69}$

$$
\mathrm{RO}_{4} \mathrm{R}^{\prime} \stackrel{k_{9}^{\prime}}{\longrightarrow} \mathrm{R}=\mathrm{O}+\mathrm{O}_{2}+\mathrm{HOR}^{\prime}
$$

Similar experimental branching ratios were reported in the literature for secondary and tertiary peroxy radicals. ${ }^{26,70}$ The experimental value is used in our model, i.e. $k_{9} / k_{9}^{\prime}=1.5$. Finally, the end-radicals obtained in eq IV are involved in similar suite of reactions. $^{71}$

\section{Kinetic Model}

Kinetic Calculations Setup. The complete set of reactions is presented in Figures 8 and 9 for in-chain and end-radical species, respectively. The respective set of differential equations is given in the Appendix. Rate constants are listed in Table 1.

The rate constants were not treated with the hindered rotor model because this correction has a marginal impact on our results. This point is discussed now. The vibrational modes at the transition state can be separated into two categories: the conserved modes which do not change significantly along the reaction path, and the transitional modes. If transitional modes are soft, like those in the long-range transition states of barrierless reactions for example, the respective partition function varies from that of a free or hindered rotor to a true vibration. If the conserved and transitional modes are decoupled, only the latter are concerned with the hindered rotor treatment because the partition functions of the conserved modes cancel in the calculation of the rate constant. However, in large polymer systems, a number of mixed low vibrational modes (internal dihedral rotations) are slightly coupled to the transitional modes. Thus, the ratio of the respective partition functions in the transition state and reactant do not cancel in the calculation of the rate constant. In a recent study, ${ }^{41,72}$ the mixed low vibrational modes in reactants and transition state were isolated, the respective set of decoupled rotations was identified and the potential energy surface spanned by this motion was computed. Such a procedure allowed calculation of decoupled hindered rotor partition functions for a set of mixed vibrational modes. A slightly different procedure is used here to estimate this correction. The multidimensional coupled hindered rotors were treated here with the multidimensional coupled free rotor model. ${ }^{73}$ The full kinetic energy matrix for coupled internal rotations was computed, not only the product of diagonal elements. ${ }^{74}$ The product of the partition functions for the coupled free rotors is proportional to the square root of this matrix. In our work, $k_{4}, k_{5}, k_{\gamma}$, and $k_{-\gamma}$ were calculated with the TST model. When such a treatment was applied to the calculation of $k_{4}$ (see Figure 4 and eq VIII), this rate constant was $0.6 \times 10^{4} \mathrm{~s}^{-1}, 75$ whereas $1.5 \times 10^{4} \mathrm{~s}^{-1}$ was obtained from harmonic oscillator partition functions at $323 \mathrm{~K}$. In Table 2, the sensitivity of the kinetic model was estimated with respect to the magnitude of the rate constants. Upscaling or downscaling $k_{4}, k_{5}, k_{\gamma}$, and $k_{-\gamma}$ by a factor of 10 had no effect on the outcome of the kinetic simulations. This scaling being much larger than the coupled free rotor correction, it was not included here. The hindered rotor partition function being intermediate between that of a free rotor and a harmonic oscillator, the effect of such a correction is within the above error range.

The mer unit in our kinetic model is $-\left(\mathrm{O}-\mathrm{CH}_{2}-\right.$ $\mathrm{CH}_{2}-\mathrm{O}-\mathrm{CH}_{2}-\mathrm{CH}_{2}$ ) - in order to account for the intramolecular reactions that involve two 1-mer units. Considering a density of $1 \mathrm{~g} / \mathrm{cm}^{3}$ and $88 \mathrm{~g} / \mathrm{mol}$ for molecular weight, the initial concentration of 2 -mer units was $10^{-2} \mathrm{~mol} / \mathrm{cm}^{3}$. Thus, $[2-\mathrm{mer}]_{0}$ is independent of chain length in our model. In addition, the initial concentration of the radical sites was set to $10^{-12} \mathrm{~mol} /$ $\mathrm{cm}^{3}$. The oxygen concentration was kept constant at $10^{-6} \mathrm{~mol} /$ $\mathrm{cm}^{3}$, a representative value of oxygen equilibrium concentration in polymer samples under atmospheric pressure. ${ }^{76-78}$ The initial concentration of other species was set to zero.

Formal kinetics assume there is a statistically uniform distribution of the reactants in the polymer medium, a hypothesis which is not valid on the macromolecular scale. In this model, polymer degradation starts from randomly distributed in-chain radicals, and the chemical reactions take place in the neighboring region about these reactive sites. Many reactions in eqs I-XIX are unimolecular and can be described by homogeneous kinetics. This model applies also to bimolecular reactions, provided oxygen and hydroxyl radicals are uniformly distributed in the matrix. While this is true for $\mathrm{O}_{2}$, this hypothesis might not be verified for hydroxyl radicals, especially in the early stages of the degradation when hydroperoxide concentrations are small.

Slight simplifications were introduced in the model. Unreactive secondary hemiformal functional groups $\mathrm{RCHOH}-\mathrm{OR}^{\prime}$ were replaced by $\mathrm{RCH}_{2}-\mathrm{OR}^{\prime}$ to keep the size of the kinetic model as low as possible. In that case, hydrogen atoms remain available for $\mathrm{H}$-abstraction reactions. If $\mathrm{RCHOH}-\mathrm{OR}^{\prime}$ was 
kept in the kinetic model system, another set of reactions specific to this species and similar to that listed for the 2-mer unit on Figures 8 and 9 would be required. The replacement of $\mathrm{RCHOH}-\mathrm{OR}^{\prime}$ by $\mathrm{RCH}_{2}-\mathrm{OR}^{\prime}$ is justified because the reactivity of the $\mathrm{H}$-atom in the $\alpha$ position of the alcohol group and in $-\mathrm{OH}$ are similar to that of in-chain PEO H-atoms. This is true for both the peroxy $\left(k_{2}\right)$ and the hydroxyl $\left(k_{6}\right)$ radical abstraction reactions. In fact, the peroxy radical hydrogen abstraction rate constant was shown to be linearly dependent on the $\mathrm{R}-\mathrm{H}$ bond strength. ${ }^{37}$ The $\mathrm{C}-\mathrm{H}$ bond strength was calculated at $298 \mathrm{~K}$ in $\mathrm{RCHOH}-\mathrm{OR}^{\prime}$ (in this species, R and $\mathrm{R}^{\prime}$ are ethylene oxide mer units) and in $\left(\mathrm{CH}_{3}\right)_{2} \mathrm{CHOH}$ because experimental rate constants are known for this species. Similar values, i.e., 93.3 and $92.4 \mathrm{kcal} / \mathrm{mol}$ were obtained respectively at the UB3P86/6-31++G(d,p) level. Thus, it is justified to use the same rate constant for $\mathrm{RCHOH}-\mathrm{OR}^{\prime}$ and $\left(\mathrm{CH}_{3}\right)_{2} \mathrm{CHOH}$. This rate constant can be deduced from the linear relationships in ref 37 (see discussion above) and the respective experimental $\mathrm{C}-\mathrm{H}$ bond strength of $\left(\mathrm{CH}_{3}\right)_{2} \mathrm{CHOH}$. This procedure yields a value that is identical to that listed for $k_{2}$ in Table 1 (in ref 37 the same $\mathrm{C}-\mathrm{H}$ bond strengths were reported for $\left(\mathrm{CH}_{3}\right)_{2} \mathrm{CHOH}$ and DME, i. e. $91 \mathrm{kcal} / \mathrm{mol})$.

Last, the experimental rate constant of the abstraction reaction of the tertiary hydrogen atom in $\left(\mathrm{CH}_{3}\right)_{2} \mathrm{CHOH}$ by hydroxyl radicals is $k_{6}(326 \mathrm{~K})=2.5 \times 10^{12} \mathrm{~cm}^{3} \mathrm{~mol}^{-1} \mathrm{~s}^{-1} .79$ The rate constant for the abstraction reaction of the hydrogen atom in the $-\mathrm{OH}$ group is 1 order of magnitude smaller and thus, can be neglected. ${ }^{80}$ The above value is a good estimate of $k_{6}$ for hemiformal species because the respective $\mathrm{C}-\mathrm{H}$ bond strengths in $\mathrm{RCHOH}-\mathrm{OR}^{\prime}$ and $\left(\mathrm{CH}_{3}\right)_{2} \mathrm{CHOH}$ are similar (see previous discussion). There is a factor of 2 between this rate constant and that listed in Table 1 for PEO. Considering that hemiformals are produced in the minor tetroxide channel $\left(k_{9}^{\prime}<k_{9}\right)$, and that $k_{2}$ and $k_{6}$ are similar for hemiformals and $\mathrm{PEO}, \mathrm{RCHOH}-\mathrm{OR}^{\prime}$ can be replaced by $\mathrm{RCH}_{2}-\mathrm{OR}^{\prime}$ in the kinetic model.

Finally, in the $\gamma$-intermolecular pathway, the mer-units with adjacent hydroperoxides, adjacent hydroperoxy/alkoxy, or adjacent peroxy/alkoxy functional groups were replaced with a species with a single $\mathrm{OOH}$ group or an alkoxy function. These modifications are shown on Figures 8 and 9.

Last, our kinetic model does not include the termination reaction of polymer radicals $\left(2 \mathrm{P}^{\bullet} \rightarrow \mathrm{P}-\mathrm{P}\right)$ because the oxygen addition reaction proceeds more rapidly. This is shown on Figures $10 \mathrm{a}$ and $11 \mathrm{a}$, where the decay of polymer radicals $\left(2 k^{\prime \prime}{ }_{8}\right.$ $\times\left[\mathrm{P}^{*}\right]$ and $\left.k_{1} \times\left[\mathrm{O}_{2}\right]\right)$ is compared. The termination reaction is diffusion controlled and the respective rate constant $\mathrm{k}^{\prime \prime}{ }_{8}(t)$ on these figures depends on polymer chain length (see discussion in previous section and eq 2). The rate constant $k^{\prime \prime 0}=10^{12} \mathrm{~cm}^{3}$ $\mathrm{mol}^{-1} \mathrm{~s}^{-1}$ was used here.

The set of stiff differential equations was solved to obtain the concentrations as a function of time. ${ }^{81}$ Results are presented in Figures $10 \mathrm{~d}$ and $11 \mathrm{~d}$ for the natural photo-oxidative ( $h v, T$ $=308 \mathrm{~K})$ and thermo-oxidative $(\Delta, T=323 \mathrm{~K})$ degradation mechanisms, respectively. In these Figures, only the concentrations that reach significant levels are represented.

Results. First, the relative quantity of esters $(E)$ and formates $(F)$ is in excellent agreement with experimental results. After 15 and $500 \mathrm{~h}, E /(E+F)$ is $19 \%$ and $50 \%$ under photo- and thermo-oxidative conditions respectively (see Figures $10 \mathrm{~d}$ and 11d), whereas $\sim 20 \%$ and $\sim 50 \%$ were obtained experimentally. ${ }^{14}$ The experimental quantities of formates in photo- and thermo- oxidative conditions, $[F]^{h v}$ and $[F]^{\Delta}$ respectively, were also compared to that obtained from our theoretical model for the same polymer sample. Experimental absorbance of the formate vibration was reported in ref 14 and measured for 15 and $504 \mathrm{~h}$ in photo- and thermo-oxidative conditions. The experimental ratio $\left([F]_{504 h}^{\Delta} /[F]_{15 h}^{h v}\right)_{\exp }$ is 0.28 and shows that less formates are obtained under thermo-oxidative conditions at the end of the measurements. This feature is correctly reproduced by our model (see Figure 12 where the concentration of esters and formates are plotted on a linear scale). However, this ratio is $\sim 2.7$ times smaller than that obtained here. In this work, if the hydroperoxide unimolecular dissociation rate constant $k_{d}$ is divided by 4 , this ratio becomes 0.34 while $E /(E+F)=43 \%$. Such a comparison shows that the induction period in our model might be smaller than expected.

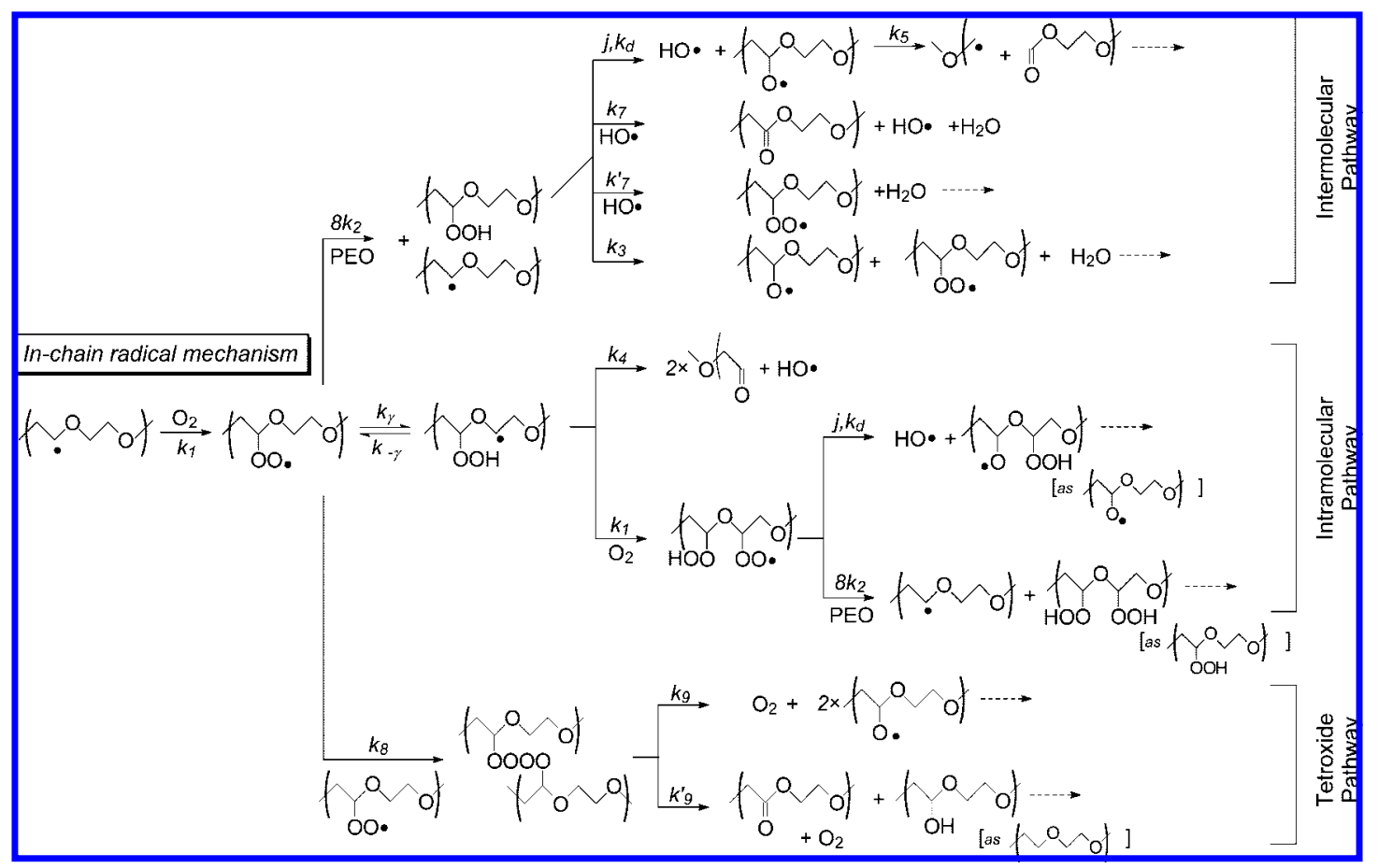

Figure 8. Oxidative degradation mechanism of PEO: in-chain radical reactions. 


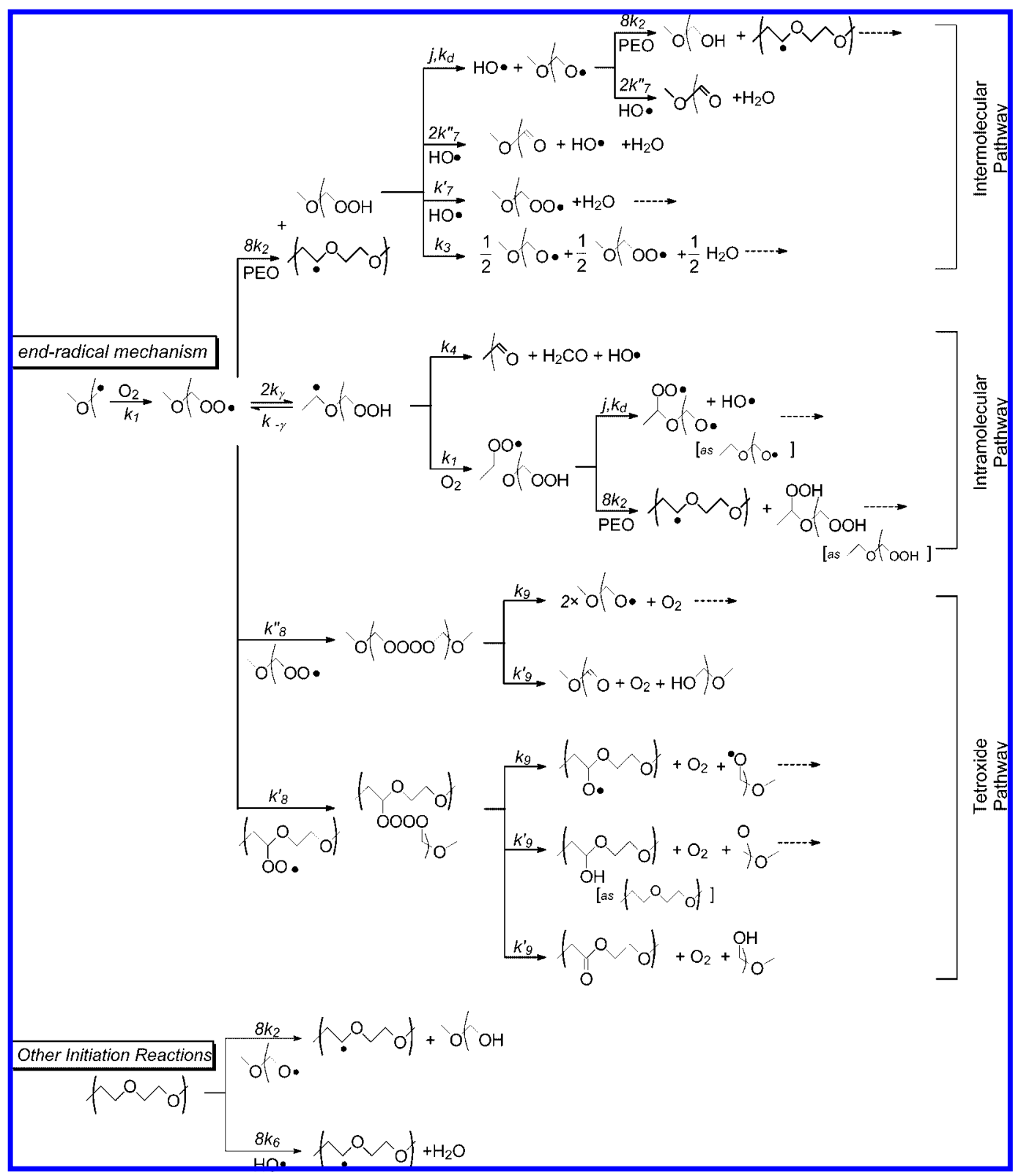

Figure 9. Oxidative degradation mechanism of PEO: the reactivity of end-radicals.

Table 1. Rate Constants Used in This Work

\begin{tabular}{lll}
\hline & photo-oxidation $(308 \mathrm{~K})$ & thermo-oxidation $(323 \mathrm{~K})$ \\
\hline$k_{1}\left(\mathrm{~cm}^{3} \mathrm{~mol}^{-1} \mathrm{~s}^{-1}\right)$ & $10^{12}$ & \\
$k_{2}\left(\mathrm{~cm}^{3} \mathrm{~mol}^{-1} \mathrm{~s}^{-1}\right)$ & 24.2 & 79.5 \\
$j, k_{d}\left(\mathrm{~s}^{-1}\right)$ & $4.5 \times 10^{-4}$ & $6.4 \times 10^{-8}$ \\
$k_{3}\left(\mathrm{~s}^{-1}\right)$ & $6.8 \times 10^{-9}$ & $3.8 \times 10^{-8}$ \\
$k_{4}\left(\mathrm{~s}^{-1}\right)$ & $5 \times 10^{3}$ & $1.5 \times 10^{4}$ \\
$k_{5}\left(\mathrm{~s}^{-1}\right)$ & $2 \times 10^{12}$ & $1.1 \times 10^{12}$ \\
$k_{6}\left(\mathrm{~cm}^{3} \mathrm{~mol}^{-1} \mathrm{~s}^{-1}\right)$ & $1.2 \times 10^{12}$ & \\
$k_{7}{ }^{a}$ & {$[10-30] \times k_{7}^{\prime} / 7.5$} & \\
$k_{7}^{\prime}\left(\mathrm{cm}^{3} \mathrm{~mol}^{-1} \mathrm{~s}^{-1}\right)$ & $5.4 \times 10^{12}$ \\
$k_{7}^{\prime \prime}$ & $\left(k_{7}+k_{7}^{\prime}\right) / 2$ \\
$k_{\gamma}\left(\mathrm{s}^{-1}\right)$ & 0.8 & 2.8 \\
$k_{-\gamma}\left(\mathrm{s}^{-1}\right)$ & $7 \times 10^{7}$ \\
$k_{8}^{0}\left(\mathrm{~cm}^{3} \mathrm{~mol}^{-1} \mathrm{~s}^{-1}\right)$ & $10^{10}$ \\
$k_{8}^{\prime 0}\left(\mathrm{~cm}^{3} \mathrm{~mol}^{-1} \mathrm{~s}^{-1}\right)$ & $10^{11}$ \\
$k_{8}^{\prime \prime 0}\left(\mathrm{~cm}^{3} \mathrm{~mol}^{-1} \mathrm{~s}^{-1}\right)$ & $10^{12}$ \\
$k_{9} / k_{9}^{\prime}$ & 1.5 \\
\multicolumn{2}{c}{${ }^{a}$ Experimental ranges are given. See text. }
\end{tabular}

In addition, as expected, aldehydes are minor products. However, the concentration of primary hemiformal groups reaches significant levels in photo-oxidative conditions.
$\mathrm{ROCH}_{2} \mathrm{OH}$ arises from the termination reactions of end-chain alkoxy radicals and the dissociation of primary tetroxides. Further degradation of this unstable species is expected but was not investigated here.

The time-range of experimental measurements is represented in Figure 12. The dashed regions are bounded to the left by induction times $(\sim 0.5 \mathrm{~h}$ and $\sim 100 \mathrm{~h}$ for photo- and thermooxidative conditions, respectively), while the right-hand boundaries indicate the end of experimental measurements $(\sim 15 \mathrm{~h}$ and $\sim 500 \mathrm{~h}$ for photo- and thermo-oxidative conditions, respectively). Experimental induction times differ significantly in photo- and thermo-oxidative conditions ( 2 orders of magnitude). This feature is accurately described by our model (see Figure 12).

Although there is good agreement between simulation and experiment, this model is most interesting because it bears the inner elementary mechanisms at play in the aging process. It is thus possible to give the fundamental reasons at the origin of the experimental differences between induction times. It is also interesting to explain why quantities of carbonyl end-products are strongly dependent on oxidative conditions. 


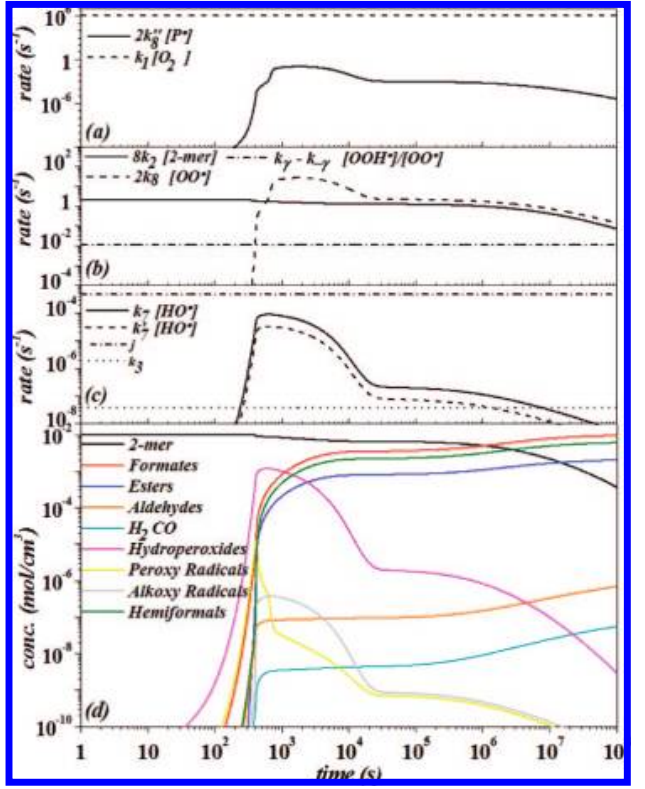

Figure 10. Photo-oxidative conditions. (a) Comparison of in-chain radical decay through the termination reaction $\left(2 k^{\prime \prime}{ }_{8}\left[\mathrm{P}^{*}\right]^{2}\right)$ and the oxygen addition reaction $\left(k_{2}\left[\mathrm{O}_{2}\right]\left[\mathrm{P}^{*}\right]\right)$. (b) Comparison of the peroxy radical decay through the intermolecular $\left(8 k_{2}\left[\mathrm{OO}^{\circ}\right][2-\mathrm{mer}]\right)$ and $\gamma$-intramolecular $\left(k_{\gamma}\left[\mathrm{OO}^{*}\right]-k_{-\gamma}\left[\mathrm{OOH}^{*}\right]\right) \mathrm{H}$-abstraction reactions, and the termination reaction $\left(2 k_{8}\left[\mathrm{oO}^{*}\right]^{2}\right)$. $\mathrm{P}^{*}, \mathrm{OO}^{*}$ and $\mathrm{OOH}^{*}$ are the $y_{1}, y_{3}$, and $y_{12}$ species listed in the Appendix. (c) Decay of hydroperoxide species through the induced dissociation $\left(k_{7} \times\left[\mathrm{HO}^{*}\right]\right)$, hydroperoxide hydrogen abstraction $\left(k_{7}^{\prime} \times\left[\mathrm{HO}^{\circ}\right]\right)$, unimolecular dissociation $(j)$, and apparent first-order bimolecular decomposition $\left(k_{3}\right)$. (d) Concentrations as a function of time.

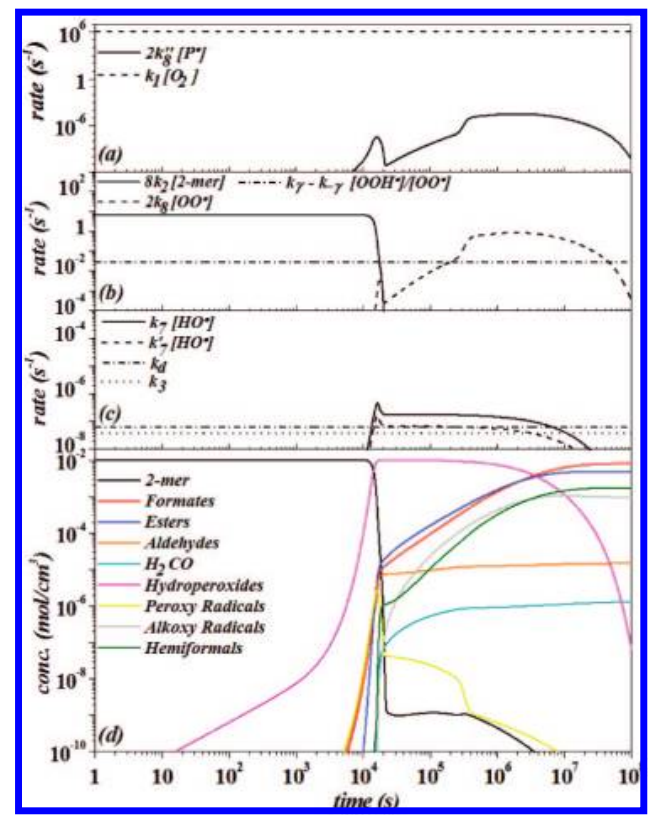

Figure 11. Same as Figure 10 for the thermo-oxidative conditions.

The models share the same set of elementary reactions, but they differ mainly by the magnitude of $j$ (or $k_{d}$ ). Moreover, in Figures 10d and 11d, hydroperoxides build up rapidly after the induction period, but larger quantities are obtained in thermooxidative conditions. The details of the degradation mechanism are now discussed.

Photo-Oxidative Conditions. The decay of peroxy radicals is compared in Figure 10b for the intermolecular $\mathrm{H}$-abstraction reaction $\left(8 k_{2} \times[2-m e r]^{82}\right)$, the termination reaction $\left(2 k_{8} \times\right.$ $\left.\left[\mathrm{OO}^{*}\right]\right)$ and the $\gamma$-intramolecular rearrangement $\left(k_{\gamma}-k_{-\gamma}\left[\mathrm{OOH}^{*}\right] /\right.$

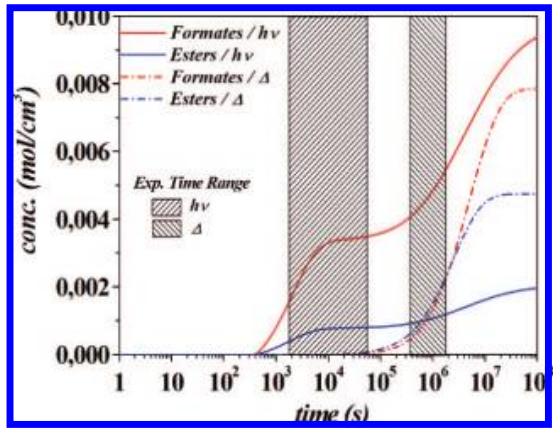

Figure 12. Linear scale plot of the concentration of esters and formates vs time in photo- and thermo-oxidative conditions. The respective experimental measurement time range is also indicated $(0.5-15 \mathrm{~h}$ for the photo oxidative conditions and 100-500 $\mathrm{h}$ under thermo-oxidative conditions).

$\left[\mathrm{OO}^{\circ}\right]$; $\mathrm{OOH}^{\bullet}$ and $\mathrm{OO}^{*}$ are the $y_{12}$ and $y_{3}$ species listed in the Appendix, respectively). Initially, as shown in this figure, peroxy radicals decay according to the intermolecular mechanism. Hydroperoxides are obtained. On Figure 10c, the decay of hydroperoxides is compared for the unimolecular dissociation $(j)$ and the induced decomposition reaction $\left(k_{7} \times\left[\mathrm{HO}^{\circ}\right]\right)$. The former being favored, formates are obtained from $\beta$-scission reactions in early stages of the degradation. At the same time, the tetroxide rate constant $k_{8}$ increases because the average polymer chain length becomes smaller. As seen in Figure 10b, the tetroxide channel takes rapidly over the intermolecular $\mathrm{H}$-abstraction reaction. This is the reason why hydroperoxide species do not build up significantly, contrarily to what is observed in thermo-oxidative conditions (Figure 11d). The peroxy termination pathway (tetroxide) yields mainly formates because $k_{9}>k_{9}^{\prime}$. Thus, in photo-oxidative conditions, formates are obtained in large quantities. In addition, the $\gamma$-intramolecular channel is not significant under photo-oxidative conditions (see Figure 10b). In these conditions, a small quantity of esters is obtained in the tetroxide pathway. Hemiformals are obtained in reactions of end-radicals.

Finally, the peroxy radical concentration decreases because it is consumed in the tetroxide pathway. At $\sim 3 \times 10^{4} \mathrm{~s}$ $(\sim 8 \mathrm{~h})$, the intermolecular $\mathrm{H}$-abstraction pathway becomes competitive again (see Figure 10b) and hydroperoxides stop their rapid decay (Figure 10d). ${ }^{83}$ At this point, after $8 \mathrm{~h}$ of irradiation, only $35 \%$ of the polymer is degraded.

Thermo-Oxidative Conditions. The mechanism is a bit more complex in thermo-oxidative conditions because many channels are competitive. Initially, peroxy radicals react also in intermolecular H-abstraction reactions (see Figure 11b). However, hydroperoxides dissociate slowly ( $k_{d}$ is small in thermo-oxidative conditions) and bond scissions are not significant. Thus, at this point, hydroperoxide decomposition has not really started yet and the tetroxide formation rate constant remains small (for $t<$ $\left.1.5 \times 10^{4} \mathrm{~s}\right)$. The hydroperoxide concentration builds up significantly (Figure 11d) because peroxy radicals react exclusively in the intermolecular $\mathrm{H}$-abstraction channel (Figure 11b). When the $\gamma$-intramolecular pathway ${ }^{84}$ becomes competitive $\left(t=1.5 \times 10^{4} \mathrm{~s}\right)$, the available in-chain $\mathrm{H}$-atoms have been replaced by hydroperoxide groups and the concentration of peroxy radicals is small. Thus, although favored, the $\gamma$-intramolecular channel does not contribute significantly to the mechanism. Moreover, in our model, the $\gamma$-intramolecular channel is less important for low molecular weight samples.

In Figure 11c, the decay of hydroperoxides is compared for the unimolecular dissociation $\left(k_{d}\right)$, the induced decomposition by hydroxyl radicals $\left(k_{7} \times\left[\mathrm{HO}^{\circ}\right]\right)$ and the hydroperoxide $\mathrm{H}$-abstraction reaction $\left(k^{\prime} \times\left[\mathrm{HO}^{\circ}\right]\right)$. The apparent first-order 
Table 2. Influence of the Scaling Factor in Photo- and Thermo-Oxidative Conditions for the High Molecular Weight Sample $^{a, b}$

\begin{tabular}{cccc}
\hline $\begin{array}{c}\text { photo-oxidative } \\
\text { conditions }\end{array}$ & $\mathrm{k}_{i} / 10$ & $k_{i} \times 1$ & $k_{i} \times 10$ \\
\hline$k_{2}$ & $0.17\left(10^{3}\right)$ & & \\
$k_{6}$ & $0.28(--)$ & $\left\{\mathbf{0 . 1 9}\left(\mathbf{4} \times \mathbf{1 0}^{2}\right)\right\}$ & $0.30\left(10^{2}\right)$ \\
$j$ & $0.23\left(10^{3}\right)$ & & $0.17\left(10^{2}\right)$ \\
$k_{7}^{\prime}$ & $0.16(--)$ & & $0.28(--)$ \\
\hline
\end{tabular}

\begin{tabular}{clll}
\hline $\begin{array}{c}\text { thermo-oxidative } \\
\text { conditions }\end{array}$ & \multicolumn{1}{c}{$k_{i} / 10$} & $k_{i} \times 1$ & \multicolumn{1}{c}{$k_{i} \times 10$} \\
\hline$k_{1}$ & $0.49(--)$ & & $0.55(--)$ \\
$k_{2}$ & $0.43\left(4 \times 10^{4}\right)$ & & $0.50\left(3 \times 10^{3}\right)$ \\
$k_{3}$ & $0.56(--)$ & & $0.26\left(9 \times 10^{3}\right)$ \\
$k_{d}^{c}$ & $0.34\left(3 \times 10^{4}\right)$ & $\left\{\mathbf{0 . 5 0}\left(\mathbf{1 . 5} \times \mathbf{1 0}^{4}\right)\right\}$ & $0.46\left(5 \times 10^{3}\right)$ \\
$k_{\gamma}$ & $0.49(-)$ & & $0.56(--)$ \\
$k_{-\gamma}$ & $0.56(--)$ & & $0.49(--)$ \\
{$\left[\mathrm{O}_{2}\right]^{d}$} & $0.49(--)$ & $0.55(--)$
\end{tabular}

\begin{tabular}{llll}
\hline & $k_{7}=10 \times k_{7}^{\prime} / 7.5$ & $k_{7}=20 \times k_{7}^{\prime} / 7.5$ & $k_{7}=30 \times k_{7}^{\prime} / 7.5$ \\
\hline$k_{7}{ }^{e}$ & $0.37(--)$ & $\mathbf{0 . 5 0}\left(\mathbf{1 . 5} \times \mathbf{1 0}^{4}\right)$ & $0.58(--)$
\end{tabular}

\begin{tabular}{lll}
\hline & $k_{7}=20 \times k_{7}^{\prime} / 3.9$ & $k_{7}=20 \times k_{7}^{\prime} / 7.5$ \\
\hline$k_{7}^{f}$ & $0.63(-)$ & $\mathbf{0 . 5 0}\left(\mathbf{1 . 5} \times \mathbf{1 0}^{4}\right)$
\end{tabular}

${ }^{a} M_{\mathrm{w}}=4,000,000 \mathrm{~g} / \mathrm{mol}$. Results were similar for the low molecular weight sample $(100,000 \mathrm{~g} / \mathrm{mol})$. The ratio esters/(esters+formates) for unscaled rate constants are listed in bold type. Only the most sensitive rate constants are listed. Induction times $(s)$ are indicated in parentheses. ${ }^{b}$-- means result is similar to that obtained with the unscaled rate constant. ${ }^{c}$ The results reach a maximum when the scaling factor is $\sim 1{ }^{d}$ The oxygen stationary concentration was upscaled or downscaled by a factor of $10{ }^{e}$ Enhancement factors between 10 and 30 are reported in the literature for $k_{7}$ between primary and tertiary sites (see text). ${ }^{f}$ Different values $\left(3.9^{58}\right.$ and $7.5^{22}$ ) were reported for the experimental branching ratio of the ester channel (eq XVI b1) and the peroxy radical channel (eq XVI b2). See text.

bimolecular dissociation rate constant $\left(k_{3}\right)$ is also plotted in this figure. After the induction period, the induced decomposition is the most favored mechanism and represents $54 \%$ of the overall hydroperoxide decomposition channel, while it is $18 \%, 18 \%$ and $10 \%$, respectively, for the unimolecular decomposition, hydroperoxide $\mathrm{H}$-abstraction and bimolecular decomposition reactions.

It was mentioned above that the unimolecular dissociation yielded formates. The hydroperoxide $\mathrm{H}$-abstraction pathway gives peroxy radicals which react in $\gamma$-intramolecular reactions, or more significantly, in the tetroxide channel. The latter yields mostly formates because $k_{9}>k_{9}^{\prime}$. Finally, the bimolecular decomposition yields alkoxy and peroxy radicals. As stated above, both species give mostly formates. Thus similar quantities of esters $(54 \%)$ and formates $(18+18+$ $10=46 \%$ ) are obtained.

Sensitivity Analysis. The sensitivity of the model was analyzed with respect to the model parameters. Rate constants were upscaled or downscaled one at a time by an order of magnitude, and the relative quantity of esters and formates was compared to that obtained from the simulation with unscaled parameters (see Table 2). Note the range of rate constants scanned by these scaling factors, i.e., 2 orders of magnitude, is much larger than actual uncertainties.

First, the ratio $E /(E+F)$ is not influenced significantly by this scaling in photo-oxidative conditions. However, the induction period is slightly sensitive to $k_{2}$ and $j$, respectively the rate constants of the peroxy radical intermolecular $\mathrm{H}$-abstraction and the photoinduced hydroperoxide dissociation. While, experimentally, it is difficult to minimize the availability of hydrogen atoms in $\mathrm{H}$-abstraction reactions $\left(k_{2}\right)$, it is easier to control the photolysis frequency of hydroperoxides. UV absorbers are now widely used in the industry to protect polymers from degradation. For PEO, upscaling (respectively downscaling) $j$ by an order of magnitude decreases (respectively increases) induction times by a factor of $\sim 3$. This effect may be larger in polymers where the induced hydroperoxide dissociation pathway (eq VII) is enhanced (more labile $\mathrm{H}$-atoms in the $\alpha$ position, for example). In thermo-oxidative conditions, our model is sensitive (see Table 2 ) to $k_{d}, k_{3}$, and $k_{7}$. For small values of $k_{d}$, the tetroxide channel gains importance and larger amounts of formates are obtained. The bimolecular decomposition $\left(k_{3}\right)$ and the competitive induced dissociation reaction $\left(k_{7}\right)$ yield formates and esters, respectively. Thus, the model is sensitive to the relative importance of these channels. Further investigations are currently under way in our laboratory to compare these rate constants for several polymers.

\section{Conclusion}

The photo- and thermo-oxidative degradation mechanism of PEO in the solid state was investigated with a theoretical kinetic model. A comprehensive set of key reactions was selected on the basis of quantum ab initio calculations and experimental kinetic data.

First, induction times were shown to be correlated to the hydroperoxide dissociation rate constant.

Second, two local minima were found in this work for the PEO alkoxy radical at the UB3P86/6-31++G(d,p) level. Considering hydroperoxide decomposition yields the more stable structure, the $\mathrm{RO}-\mathrm{OH}$ bond dissociation energy is significantly lowered and the preferred hydroperoxide dissociation pathway is the unimolecular decomposition.

Last, the degradation mechanism of PEO is different whether under photo- or thermo-oxidative conditions. In photo-oxidative conditions, the peroxy radicals react first in intermolecular $\mathrm{H}$-abstraction reactions. The photoinduced dissociation of hydroperoxides is fast and formates are produced rapidly. Simultaneously, the peroxy termination reaction rate constant increases as polymer degradation $(\beta$ scissions) continues. This phenomenon prevents hydroperoxides to build up significantly. Large quantities of formates are obtained in this case. In thermo-oxidative conditions, the peroxy radicals react successively in intermolecular $\mathrm{H}$ abstraction reactions and termination reactions. However, while hydroperoxide species dissociate unimolecularly in photo-oxidative conditions, three extra channels compete in thermo-oxidative conditions: the induced decomposition by hydroxyl radicals amounts up to $54 \%$ of the overall hydroperoxide decomposition channel (esters are obtained), while $18 \%$ and $10 \%$ are obtained in the hydroperoxide $\mathrm{H}$-abstraction reaction (formates) and the bimolecular decomposition (formates), respectively. The unimolecular hydroperoxide dissociation yields mainly formates and represents $18 \%$ of the overall channel. In these conditions, similar quantities of esters and formates are obtained.

The $\gamma$-intramolecular pathway is shown to bear minor significance.

Many reactions presented in this work participate in polymer synthesis, pyrolysis or natural degradation processes. These are often difficult to characterize experimentally. In this work, we provided quantitative kinetic data for such purposes. In addition, we have shown the importance of several elementary reactions on a model polymer structure in order to understand the inner mechanisms of lowtemperature polymer degradation.

\section{Appendix}

The set of differential equations used in this work. Respective species are listed in Table 3. 


$$
\begin{aligned}
& y_{1}^{\prime}=-k_{1} y_{1} y_{2}+8 k_{2} y_{4}\left(y_{3}+y_{10}+y_{14}+y_{16}+y_{19}\right)+8 k_{6} y_{4} y_{6} \quad y_{8}^{\prime}=k_{5} y_{11}+2 k^{\prime \prime}{ }_{7} y_{6}\left(y_{15}+y_{16}\right)+k_{9}^{\prime}\left(y_{21}+y_{22}\right) \\
& y_{2}^{\prime}=0 \quad y_{9}^{\prime}=k_{7} y_{5} y_{6}+k_{9}^{\prime}\left(y_{20}+y_{21}\right) \\
& y_{3}^{\prime}=k_{1} y_{1} y_{2}-8 k_{2} y_{3} y_{4}-k_{\gamma} y_{3}+k_{-\gamma} y_{12}+k_{7}^{\prime} y_{5} y_{6}-2 k_{8} y_{3}^{2}-\quad y_{10}^{\prime}=k_{1} y_{2} y_{12}-8 k_{2} y_{4} y_{10}-j y_{10} \\
& k_{8}^{\prime} y_{3} y_{14}+0.5 k_{3} y_{5} \\
& y_{11}^{\prime}=j\left(y_{5}+y_{10}\right)-k_{5} y_{11}+k_{9}\left(2 y_{20}+y_{21}\right)+0.5 k_{3} y_{5} \\
& y_{4}^{\prime}=-8 k_{2} y_{4}\left(y_{3}+y_{10}+y_{14}+y_{16}+y_{19}\right)-8 k_{6} y_{4} y_{6}+ \\
& k_{9}^{\prime}\left(y_{20}+y_{21}\right) \quad y_{12}^{\prime}=k_{\gamma} y_{3}-k_{-\gamma} y_{12}-k_{4} y_{12}-k_{1} y_{2} y_{12} \\
& y_{5}^{\prime}=8 k_{2} y_{3} y_{4}-j y_{5}-\left(k_{7}+k_{7}^{\prime}\right) y_{5} y_{6}-k_{3} y_{5}+8 k_{2} y_{4} y_{10} \quad y_{13}^{\prime}=k_{4}\left(2 y_{12}+y_{18}\right) \\
& y_{6}^{\prime}=j\left(y_{5}+y_{10}+y_{15}+y_{19}\right)+k_{4}\left(y_{12}+y_{18}\right)-8 k_{6} y_{4} y_{6}-\quad y_{14}^{\prime}=k_{1} y_{7} y_{2}-8 k_{2} y_{4} y_{14}+k_{7}^{\prime} y_{6} y_{15}-2 k_{y} y_{14}+k_{-\gamma} y_{18}- \\
& k_{7}^{\prime} y_{6}\left(y_{5}+y_{15}\right)-2 k^{\prime \prime}{ }_{7} y_{6} y_{16} \\
& k_{8}^{\prime} y_{3} y_{14}-2 k^{\prime \prime}{ }_{8} y_{14}^{2}+0.5 k_{3} y_{15} \\
& y_{7}^{\prime}=k_{5} y_{11}-k_{1} y_{2} y_{7} \\
& y_{15}^{\prime}=8 k_{2} y_{4} y_{14}-j y_{15}-\left(k_{7}^{\prime}+2 k_{7}^{\prime \prime}\right) y_{6} y_{15}-k_{3} y_{15}+8 k_{2} y_{4} y_{19}
\end{aligned}
$$

\begin{tabular}{|c|c|c|c|c|c|}
\hline & Species & Name & & Species & Name \\
\hline$y_{l}$ & & & $y_{13}$ & & Aldehyde \\
\hline$y_{2}$ & $\mathrm{O}_{2}$ & & $y_{14}$ & & $\begin{array}{c}\text { Primary Peroxy } \\
\text { Radical }\end{array}$ \\
\hline$y_{3}$ & & $\begin{array}{c}\text { Secondary } \\
\text { Peroxy Radical }\end{array}$ & $y_{15}$ & & $\begin{array}{c}\text { Primary } \\
\text { Hydroperoxide }\end{array}$ \\
\hline$y_{4}$ & PEO & & $y_{16}$ & & $\begin{array}{l}\text { Primary Alkoxy } \\
\text { Radical }\end{array}$ \\
\hline$y_{5}$ & OOH & $\begin{array}{c}\text { Secondary } \\
\text { Hydroperoxide }\end{array}$ & $y_{17}$ & $\mathrm{H}_{2} \mathrm{CO}$ & Formaldehyde \\
\hline$y_{6}$ & $\mathrm{HO} \cdot$ & & $y_{18}$ & & \\
\hline$y_{7}$ & & End-Radical & $y_{19}$ & & \\
\hline$y_{8}$ & & Formiate & $y_{20}$ & & $\begin{array}{c}\text { Tetroxide } \\
\text { (Secondary/Secondary) }\end{array}$ \\
\hline$y_{9}$ & & Ester & $y_{21}$ & & $\begin{array}{c}\text { Tetroxide } \\
\text { (Secondary/Primary) }\end{array}$ \\
\hline $\begin{array}{l}y_{10} \\
y_{11}\end{array}$ & & $\begin{array}{c}\text { Secondary } \\
\text { Alkoxy Radical }\end{array}$ & $y_{22}$ & $\mathrm{l}_{\mathrm{O}}^{\mathrm{H}}$ & $\begin{array}{c}\text { Tetroxide } \\
\text { (Primary/Primary) } \\
\text { Hemiformal }\end{array}$ \\
\hline
\end{tabular}




$$
\begin{aligned}
y^{\prime}{ }_{16}=j y_{15}-2 k^{\prime \prime}{ }_{7} y_{6} y_{16}-8 k_{2} y_{4} y_{16}+k_{9}\left(2 y_{22}+\right. & \left.y_{21}\right)+ \\
& 0.5 k_{3} y_{15}+j y_{19}
\end{aligned}
$$$$
y_{17}^{\prime}=k_{4} y_{18}
$$$$
y_{18}^{\prime}=2 k_{\gamma} y_{14}-k_{-\gamma} y_{18}-k_{4} y_{18}-k_{1} y_{2} y_{18}
$$$$
y_{19}^{\prime}=k_{1} y_{2} y_{18}-8 k_{2} y_{4} y_{19}-j y_{19}
$$$$
y_{20}^{\prime}=k_{8} y_{3}^{2}-\left(k_{9}+k_{9}^{\prime}\right) y_{20}
$$$$
y_{21}^{\prime}=k_{8}^{\prime} y_{3} y_{14}-\left(k_{9}+2 k_{9}^{\prime}\right) y_{21}
$$$$
y_{22}^{\prime}=k_{8}^{\prime \prime} y_{14}{ }^{2}-\left(k_{9}+k_{9}^{\prime}\right) y_{22}
$$$$
y_{23}^{\prime}=8 k_{2} y_{4} y_{16}+k_{9}^{\prime}\left(y_{21}+y_{22}\right)
$$

Acknowledgment. The author would like to thank S. MorlatThérias and Pr. J.-L. Gardette for useful discussions.

\section{References and Notes}

(1) Lane, G. A., Ed. Solar Energy Storage: Latent Heat Materials; CRC Press: New York, 1986; Vol II., Technology.

(2) Bailey, F. E., Jr.; Koleske, J. V. Poly(ethylene oxide); Academic Press: London, 1976.

(3) Harris, J. M. , Ed. Poly(ethylene glycol) Chemistry: Biotechnical and Biomedical Applications; Plenum Press: New York, 1992.

(4) Madorsky, S. L.; Strauss, S. J. Polvm. Sci. 1959, 36, 183-194.

(5) Voorhees, K. J.; Baugh, S. F.; Stevenson, D. N. J. Anal. Appl. Pyrolvsis 1994, 30, 47-57.

(6) Arisawa, H.; Brill, T. B. Combust. Flame 1997, 109, 87-104.

(7) Arisawa, H.; Brill, T. B. Combust. Flame 1997, 109, 105-112.

(8) Lattimer, R. P. J. Anal. Appl. Pyrolvsis 2000, 56, 61-78.

(9) Vijayalakshmi, S. P.; Madras, G. J. Appl. Polvm. Sci. 2006, 101, $233-$ 240

(10) Han, S.; Kim, C.; Kwon, D. Polvm. Deg. Stab. 1995, 47, 203-208.

(11) Glastrup, J. Polvm. Deg. Stab. 1996, 52, 217-222.

(12) Han, S.; Kim, C.; Kwon, D. Polvmer 1997, 38, 317-323.

(13) Gallet, G.; Erlandsson, B.; Albertsson, A.-C.; Karlsson, S. Polvm. Deg. Stab. 2002, 77, 55-66.

(14) Morlat, S.; Gardette, J. -L. Polvmer 2001, 42, 6071-6079.

(15) Morlat, S.; Gardette, J. -L. Polvmer 2003, 44, 7891-7897.

(16) Fraisse, F.; Morlat-Thérias, S.; Gardette, J.-L.; Nedelec, J.-M.; Baba, M. J. Phvs. Chem. B 2006, 110, 14678-14684.

(17) Soto-Oviedo, M. A.; De Paoli, M.-A. Polvm. Deg. Stab. 2002, 76, 219-225.

(18) Grassie, N.; Perdomo Mendoza, G. A. Polvm. Deg. Stab. 1984, 9 , $155-165$.

(19) Fares, M. M.; Hacaloglu, J.; Suzer, S. Eur. Polvm. J. 1994, 30, 845850.

(20) Calahorra, E.; Cortazar, M.; Guzmàn, G. M. J. Polvm. Sci.: Polvm. Lett. Ed. 1985, 23, 257-260.

(21) Pielichowski, K.; Flejtuch, K. J. Anal. Appl. Pyrolysis 2005, 73, 131138.

(22) Vaghjiani, G. L.; Ravishankara, A. R. J. Phvs. Chem. 1989, 93, 1948 1959.

(23) Mkhatresh, O. A.; Heatley, F. Macromol. Chem. Phys. 2002, 203, $2273-2280$

(24) Gugumus, F. Polym. Deg. Stab. 2000, 68, 337-352.

(25) Roehl, C. M.; Marka, Z.; Fry, J. L.; Wennberg, P. O. Atmos. Chem. Phys. 2007, 7, 713-720.

(26) Wallington, T. J.; Dagaut, P.; Kurylo, M. J. Chem. Rev. 1992, 92, 667-710.

(27) Kuzina, S. I.; Mikhailov, A. I. J. Photochem. Photobiol. A: Chem. 2004, 163, 367-372.

(28) Gugumus, F. Polvm. Deg. Stab. 2001, 74, 327-339.
(29) Gaussian 03, Revision B.05, Frisch, M. J.; Trucks, G. W.; Schlegel, H. B.; Scuseria, G. E.; Robb, M. A.; Cheeseman, J. R.; Montgomery, Jr., J. A.; Vreven, T.; Kudin, K. N.; Burant, J. C.; Millam, J. M.; Iyengar, S. S.; Tomasi, J.; Barone, V.; Mennucci, B.; Cossi, M.; Scalmani, G.; Rega, N.; Petersson, G. A.; Nakatsuji, H.; Hada, M.; Ehara, M.; Toyota, K.; Fukuda, R.; Hasegawa, J.; Ishida, M.; Nakajima, T.; Honda, Y.; Kitao, O.; Nakai, H.; Klene, M.; Li, X.; Knox, J. E.; Hratchian, H. P.; Cross, J. B.; Bakken, V.; Adamo, C.; Jaramillo, J.; Gomperts, R.; Stratmann, R. E.; Yazyev, O.; Austin, A. J.; Cammi, R.; Pomelli, C.; Ochterski, J. W.; Ayala, P. Y.; Morokuma, K.; Voth, G. A.; Salvador, P.; Dannenberg, J. J.; Zakrzewski, V. G.; Dapprich, S.; Daniels, A. D.; Strain, M. C.; Farkas, O.; Malick, D. K.; Rabuck, A. D.; Raghavachari, K.; Foresman, J. B.; Ortiz, J. V.; Cui, Q.; Baboul, A. G.; Clifford, S.; Cioslowski, J.; Stefanov, B. B.; Liu, G.; Liashenko, A.; Piskorz, P.; Komaromi, I.; Martin, R. L.; Fox, D. J.; Keith, T.; Al-Laham, M. A.; Peng, C. Y.; Nanayakkara, A.; Challacombe, M.; Gill, P. M. W.; Johnson, B.; Chen, W.; Wong, M. W.; Gonzalez, C.; Pople, J. A. Gaussian, Inc.: Wallingford CT, 2004.

(30) Becke, A. D. J. Chem. Phys. 1996, 104, 1040-1046.

(31) Marsal, P.; Roche, M.; Tordo, P.; de Sainte Claire, P. J. Phys. Chem. A 1999, 103, 2899-2905.

(32) CTST rate constants were calculated with the Absolute Rate Theory program of Pr. W. L. Hase.

(33) Truhlar, D. G. J. Comput. Chem. 1991, 12, 266-270.

(34) Ingold, K. U. Acc. Chem. Res. 1969, 2, 1-9.

(35) Bozzelli, J. W.; Sheng, C. J. Phys. Chem. A. 2002, 106, 1113-1121.

(36) Kamińska, A.; Kaczmarek, H.; Kowalonek, J. Polvmer 1999, 40, 57815791.

(37) Korcek, S.; Chenier, J. H. B.; Howard, J. A.; Ingold, K. U. Can. J. Chem. 1972, 50, 2285-2297.

(38) For information, the authors in ref 37 suggest $\Delta H^{\circ}\left(\mathrm{CH}_{3} \mathrm{OCH}_{2}-\mathrm{H}, 303\right.$ $\mathrm{K})=91 \mathrm{kcal} / \mathrm{mol}$ is the preferred value for use in their linear relationship.

(39) Blitz, M. A.; Heard, D. E.; Pilling, M. J. J. Photochem. Photobiol. A: Chem. 2005, 176, 107-113.

(40) Vereecken, L.; Nguyen, T. L.; Hermans, I.; Peeters, J. Chem. Phvs. Lett. 2004, 393, 432-436.

(41) Pfaendtner, J.; Yu, X.; Broadbelt, L. J. J. Phys. Chem. A 2006, 110, 10863-10871.

(42) Chien, J. C. W. J. Polvm. Sci., Part A-1 1968, 6, 375-379.

(43) Chien, J. C. W.; Vandenberg, E. J.; Jabloner, H. J. Polvm. Sci. Part A-1 1968, 6, 381-392.

(44) Zolotova, N. V.; Denisov, E. T. J. Polym. Sci., Part A-1 1971, 9, 33113320.

(45) Zlatkevich, L. Polvm. Deg. Stab. 2004, 83, 369-371.

(46) Hiatt, R.; Irwin, K. C. J. Org. Chem. 1968, 33, 1436-1441.

(47) Benson, S. W J. Chem. Phvs. 1964, 40, 1007-1013.

(48) Gugumus, F. Polvm. Deg. Stab. 2000, 69, 23-34.

(49) Pickard, J. M.; Jones, E. G. Energy Fuels 1998, 12, 1241-1244.

(50) Khelidj, N.; Colin, X.; Audouin, L.; Verdu, J.; Monchy-Leroy, C.; Prunier, V. Polvm. Deg. Stab. 2006, 91, 1598-1605.

(51) Gugumus, F. Polvm. Deg. Stab. 2008, 93, 546-556.

(52) Gijsman, P.; Hennekens, J.; Vincent, J. Polvm. Deg. Stab. 1993, 42, 95-105.

(53) Extrapolation of Gijsman's work yields $k(308 \mathrm{~K})=6.8 \times 10^{-9} \mathrm{~s}^{-1}$.

(54) Monod, A.; Chevallier, E.; Durand Jolibois, R.; Doussin, J. F.; PicquetVarrault, B.; Carlier, P. Atmos. Environ. 2007, 41, 2412-2426.

(55) Decker, C.; Marchal, J. Makromol. Chem. 1973, 166, 155-178.

(56) Mellouki, A.; Teton, S.; Le Bras, G. Int. J. Chem. Kinet. 1995, 27, 791-805.

(57) DeMore, W. B.; Bayes, K. D. J. Phvs. Chem. A 1999, 103, 26492654.

(58) Niki, H.; Maker, P. D.; Savage, C. M.; Breitenbach, L. P. J. Phvs. Chem. 1983, 87, 2190-2193.

(59) Ogura, T.; Miyoshi, A.; Koshi, M. Phvs. Chem. Chem. Phvs. 2007, 9, 5133-5142.

(60) Bravo-Pérez, G.; Alvarez-Idaboy, J. R.; Jiménez, A. G.; Cruz-Torres, A. Chem. Phys. 2005, 310, 213-223.

(61) Masuda, T.; Nakano, S.; Yoshihara, K.; Kondo, M. J. Radiat. Res. 1976, 17, 63-68.

(62) Bartlett, P. D.; Traylor, T. G. J. Am. Chem. Soc. 1963, 85, 24072410.

(63) Factor, A.; Russell, C. A.; Traylor, T. G. J.Am. Chem. Soc. 1965, 87, 3692-3698.

(64) Dagaut, P.; Wallington, T. J.; Kurylo, M. J. J. Photochem. Photobiol. A. Chem. 1989, 48, 187-198.

(65) Cussler, E. L. Diffusion: Mass Tranfer in Fluid Systems; Cambridge University Press: Cambridge, U.K., 1997.

(66) Kruse, T. M.; Woo, O. S.; Wong, H.-W.; Khan, S. S.; Broadbelt, L. J. Macromolecules 2002, 35, 7830-7844.

(67) Fuchs, M.; Schweizer, K. S. Macromolecules 1997, 30, 5156-5171.

(68) $n_{0}=2273$ or 90909 in order to match experimental conditions. 
(69) Furimsky, E.; Howard, J. A.; Selwyn, J. Can. J. Chem. 1980, 58, 677680.

(70) Lindsay, D.; Howard, J. A.; Horswill, E. C.; Iton, L.; Ingold, K. U.; Cobbley, T.; L1, A. Can. J. Chem. 1973, 51, 870-880.

(71) The intermolecular $\mathrm{H}$-abstraction reaction is included in the model for primary alkoxy radicals because the formate pathway is not available to this species. For in-chain alkoxy radicals, the rate constant of the $\beta$-scission mechanism is larger than that of intermolecular $\mathrm{H}$-abstraction reactions.

(72) Pfaendtner, J.; Yu, X.; Broadbelt, L. J. Theor. Chem. Acc. 2007, 118, 881-898.

(73) Kilpatrick, J. E.; Pitzer, K. S. J. Chem. Phvs. 1949, 17, 1064-1075.

(74) See Appendix in: Kharroubi, M.; de Sainte Claire, P. J. Phvs. Chem. A 2003, 107, 4483-4489.

(75) Low frequency dihedral rotational motions were identified in the reactant and the transition state $\left(\mathrm{TS}_{4}\right.$ in Figure 4). The vibrational frequencies in the reactant and TS were $28,48,64,72,82,224,229$ $\mathrm{cm}^{-1}$ and $26,58,73,84,224,224 \mathrm{~cm}^{-1}$, respectively. Italicized frequencies correspond to the rotational modes that are coupled.

(76) Van Krevelen, D. W. Properties of Polymers, their Estimation and Correlation with Chemical Structure; Elsevier: New York, 1976.
(77) Colin, X.; Fayolle, B.; Audouin, L.; Verdu, J. Int. J. Chem. Kinet. 2006, 38, 666-676.

(78) O’Brien, A. K.; Bowman, C. N. Macromolecules 2006, 39, 25012506.

(79) Dunlop, J. R.; Tully, F. P. J. Phvs. Chem. 1993, 97, 6457-6464.

(80) Luo, N.; Kombo, D. C.; Osman, R. J. Phvs. Chem. A 1997, 101, 926936.

(81) The Matlab package and the ode15s solver, a variable order solver based on the numerical differentiation formulas, was used to solve the set of differential equations listed in the Appendix.

(82) [2-mer] in this expression is the concentration of a polymer unit that contains two 1-mer units.

(83) This reflects competition between the decrease of average chain length and the decay of peroxy radicals through the tetroxide pathway.

(84) $k_{-\gamma}$ was estimated with great accuracy in ref 85 . However, the author was skeptical about this value, arguing that this would require an unreasonable low activation energy of $\mathrm{H}$-abstraction by peroxy radicals. In our work, we found that $k_{-}$is mainly driven by entropic factors.

(85) Gugumus, F. Polvm. Deg. Stab. 2002, 76, 329-340. 